\title{
Environmental Temperature and Thermal Indices: What Is the Most Effective Predictor of Heat-Related Mortality in Different Geographical Contexts?
}

\author{
Marco Morabito, ${ }^{1,2,3}$ Alfonso Crisci, ${ }^{4}$ Alessandro Messeri, ${ }^{2}$ Valerio Capecchi, ${ }^{4}$ \\ Pietro Amedeo Modesti, ${ }^{2,5}$ Gian Franco Gensini, ${ }^{2,5}$ and Simone Orlandini ${ }^{1,2,3}$ \\ ${ }^{1}$ Department of Agrifood Production and Environmental Sciences, University of Florence, Piazzale delle Cascine 18, \\ 50144 Florence, Italy \\ ${ }^{2}$ Interdepartmental Centre of Bioclimatology, University of Florence, Piazzale delle Cascine 18, 50144 Florence, Italy \\ ${ }^{3}$ Center for Civil Protection and Risk Studies, University of Florence (CESPRO), Viale Morgagni 48, 50134 Florence, Italy \\ ${ }^{4}$ Institute of Biometeorology, National Research Council, Via Giovanni Caproni 8, 50145 Florence, Italy \\ ${ }^{5}$ Clinica Medica e Cardiologia, University of Florence, Viale Morgagni 85, 50134 Florence, Italy
}

Correspondence should be addressed to Marco Morabito; marco.morabito@unifi.it

Received 13 August 2013; Accepted 18 October 2013; Published 8 January 2014

Academic Editors: J. Pinto and M. Saez

Copyright (C) 2014 Marco Morabito et al. This is an open access article distributed under the Creative Commons Attribution License, which permits unrestricted use, distribution, and reproduction in any medium, provided the original work is properly cited.

The aim of this study is to identify the most effective thermal predictor of heat-related very-elderly mortality in two cities located in different geographical contexts of central Italy. We tested the hypothesis that use of the state-of-the-art rational thermal indices, the Universal Thermal Climate Index (UTCI), might provide an improvement in predicting heat-related mortality with respect to other predictors. Data regarding very elderly people ( $\geq 75$ years) who died in inland and coastal cities from 2006 to 2008 (MayOctober) and meteorological and air pollution were obtained from the regional mortality and environmental archives. Rational (UTCI) and direct thermal indices represented by a set of bivariate/multivariate apparent temperature indices were assessed. Correlation analyses and generalized additive models were applied. The Akaike weights were used for the best model selection. Direct multivariate indices showed the highest correlations with UTCI and were also selected as the best thermal predictors of heat-related mortality for both inland and coastal cities. Conversely, the UTCI was never identified as the best thermal predictor. The use of direct multivariate indices, which also account for the extra effect of wind speed and/or solar radiation, revealed the best fitting with all-cause, very-elderly mortality attributable to heat stress.

\section{Introduction}

The relationship between high environmental temperature and human mortality has been widely investigated and at the present time a large amount of scientific studies and detailed reviews are available for people living in different geographical areas [1-5]. However, the correct interpretation and comparison of results from environmental epidemiological studies are not immediate because different thermal/temperature based health-impact indicators have been adopted. For example, several authors used air temperature variables (such as daily average, maximum, and minimum air temperature) as environmental predictors of human mortality $[3,6,7]$, while others used alternative temperature metrics which condense all the extra meteorological effects (i.e., air humidity, wind speed, and solar radiation) into a single number derived by means of more or less complex thermal indices [811]. Thermal indices are useful tools for summarizing the interaction of thermal environmental stressors on humans. Thermal indices can be categorized by direct (based on direct measurements of environmental variables), empirical (based on objective and subjective stress), or rational (based on calculations involving the human heat balance) indices [12]. Most studies examined to evaluate the impact of heat stress on mortality mainly used direct indices, especially because they are quick and easy to use and usually take into account the 
combined effect of only two main meteorological variables for thermal comfort evaluations (air temperature and humidity), normally available from regular measurements of typical weather stations. Further direct indices also allow for including the combined effect of other environmental variables, such as wind speed and occasionally, depending on data availability, solar radiation [13], both of which are important for the outdoor thermal comfort assessment. However, at the present time, the application of these indices in the field of heat-related mortality is very rare [14]. While only a small number of epidemiological studies have ever attempted to use more complex and complete rational indices [15], the newly developed Universal Thermal Climate Index (UTCI) [16] that represents the state-of-the-art in outdoor thermal comfort assessments has never been employed.

In a recent study [12], several authors reported a detailed comparison of UTCI with a selected set of thermal indices and stated that direct indices (i.e., apparent temperature) are less correlated with UTCI than other indices derived from the human heat budget model. The authors claimed that one of the possible causes of unconformity is the lack of the radiation factor in the algorithm equations.

Currently, it is very difficult to compare the results of heatrelated mortality from studies that used different predictors such as air temperature variables or thermal indices, and several significant doubts regarding the application of one or other environmental indicator exist among researchers involved in environmental epidemiological studies. In particular, what is the correlation pattern among different temperature and thermal index indicators, especially when the results in geographical areas are compared with very different weather conditions (i.e., strong winds, high humidity, etc.)? Consequently, what is the difference in the predicted heatrelated mortality if different temperature variables or thermal index indicators are considered? Are there significant differences when different climatic conditions and geographical locations are taken into account? In short, what is the most effective thermal indicator of heat-related mortality?

In previous studies $[14,17-19]$ the authors tried to address this issue but only simple thermal indices (generally thermohygrometric indices) were considered and the UTCI was never taken into account.

For this reason, the main aim of this study is to identify the most effective thermal/air temperature indicators for predicting heat-related mortality of the very elderly in two cities with different geographical characteristics based mainly on their distance from the Tyrrhenian Sea (coastal and inland plain cities). We put the hypothesis to the test that the use of the state of the art to assess outdoor thermal comfort/discomfort (UTCI) might provide an effective improvement in predicting heat-related mortality with respect to direct thermal indices or simple air temperature variables currently used in the literature. Furthermore, the potentially different impact on mortality due to environmental heat conditions is also investigated by using two types of meteorological data sources coming from urban and suburban weather stations. This information could prove to be very useful in developing preventive measures and for implementing local public health emergency plans related to heat-stress conditions.

\section{Material and Methods}

2.1. Mortality Data and Study Area. The health outcome data consisted of residents of the two major inland (Florence) and coastal (Livorno) cities in the Tuscany region (Central Italy) who died of nonviolent causes during the hottest period of the year (May 1 to October 31) from 2006 to 2008. Non-accidental mortality data (ICD9 < 800) were provided by the Mortality Registry of the Tuscany region. Very elderly residents $(\geq 75$ years old) who died of nonviolent causes in the two cities were selected for the analyses $(n=3,852$ in Florence and $n=1,942$ in Livorno).

The cities considered in this study are located in different geographical contexts in terms of morphological and climatic conditions. (a) Florence is an inland plain city located $80 \mathrm{~km}$ from the Tyrrhenian Sea at an average altitude of $50 \mathrm{~m}$ a.s.l. (lat. $43^{\circ} 46^{\prime} 17^{\prime \prime} \mathrm{N}$; long. $11^{\circ} 15^{\prime} 15^{\prime \prime} \mathrm{E}$ ). The average urban population density for the 3 -year period studied was 3,570 inhabitants per $\mathrm{km}^{2}$ (the highest population density in the Tuscany region). The percentage of the very elderly (age $\geq 75$ years) population was $13.6 \%$. (b) Livorno is a coastal plain city at about $10 \mathrm{~m}$ a.s.l. with its port on the Tyrrhenian Sea (lat. $43^{\circ} 33^{\prime} 0^{\prime \prime} \mathrm{N}$; long. $\left.10^{\circ} 19^{\prime} 0^{\prime \prime} \mathrm{E}\right)$. The average urban population density was 1,540 inhabitants per $\mathrm{km}^{2}$ (the highest population density in coastal Tuscan cities). The percentage of the very elderly population was $12.1 \%$.

In regard to the climatic features of the areas studied, July and August are the warmest months in both cities investigated, while the coldest months are December and January. The inland plain city is characterized by higher/lower temperatures than the coastal plain city. Furthermore, there is a wide daily temperature range in the inland city and during the warmest months. Conversely, the coastal plain city is generally characterized by a milder climate due to its close vicinity to the Tyrrhenian Sea, and it also has the shortest daily temperature range with rare extreme temperatures.

\subsection{Meteorological and Environmental Pollution Data.} Hourly meteorological data regarding air temperature $\left(T_{\text {air }}\right.$, $\left.{ }^{\circ} \mathrm{C}\right)$, relative humidity $(\mathrm{RH}, \%), 10 \mathrm{~m}$ high horizontal wind speed $\left(V_{10}, \mathrm{~m} \mathrm{~s}^{-1}\right)$, and global radiation $\left(\mathrm{GR}, \mathrm{W} \mathrm{m}{ }^{-2}\right)$ were provided by four meteorological stations managed by the Regional Weather Service of Tuscany. Meteorological data covered the warmest period of the year (May-October) from 2006 to 2008.

Two of these meteorological stations were located in urban districts, and in particular, in two green areas of the city centers of Florence and Livorno. The other two stations were located in residential districts in the flat north-west area of Florence and on the coast (about $100 \mathrm{~m}$ from the sea) of Livorno.

For the same period, air pollution data, including daily average values of ambient particulate concentrations with aerodynamic diameter $\leq 10 \mu \mathrm{m}\left(\mathrm{PM}_{10}, \mu \mathrm{g} \mathrm{m}^{-3}\right)$, nitrogen dioxide $\left(\mathrm{NO}_{2}, \mu \mathrm{g} \mathrm{m}^{-3}\right)$, sulfur dioxide $\left(\mathrm{SO}_{2}, \mu \mathrm{g} \mathrm{m}^{-3}\right)$, carbon 
monoxide $\left(\mathrm{CO}, \mathrm{mg} \mathrm{m}^{-3}\right)$, and ozone $\left(\mathrm{O}_{3}, \mu \mathrm{g} \mathrm{m}^{-3}\right)$, were obtained from the Environmental Protection Agency of Tuscany. Daily pollutant concentrations were averaged from available monitoring stations located in each urban and suburban area of Florence and Livorno. The number of monitoring sites generally varied from two to five pollution stations depending on the pollutant monitored.

During the study period, the methods and instruments of the monitoring sites, classified as "urban background" (based on European and Italian air quality legislation), were homogeneous and compliant with the quality assurance criteria. Furthermore, based on previous studies in the same geographical areas $[20,21]$, the selected environmental monitoring sites showed homogeneous air-quality levels and offered good representation of the background exposure of the general population in urban areas.

2.3. Biometeorological Indices Assessment. Three direct biometeorological indices (apparent temperature indices derived from Steadman's studies) and one rational index (Universal Thermal Climate Index) were assessed.

The apparent temperature (AT) is represented by a set of simple computational formulas which describe the combined effect of temperature and humidity, also taking into account the extra effects of wind speed and solar radiation, by measuring the thermal comfort of a typical human walking at $1.4 \mathrm{~m} \mathrm{~s}^{-1}$ and generating $177 \mathrm{~W} \mathrm{~m}^{-2}$ of total body surface $[13,22-24]$. AT is always expressed in ${ }^{\circ} \mathrm{C}$ and for this reason it is easily interpreted by general users.

The three versions of apparent temperature (AT) indices used in this study are the following.

(i) The indoor $\mathrm{AT}\left(\mathrm{AT}_{\text {ind }}\right)$ only takes the combined effect of air temperature and humidity into consideration; this index is assessed by the following formula:

$$
\mathrm{AT}_{\text {ind }}=0.89 T_{\text {air }}+0.382 e-2.56 .
$$

(ii) The shade $\mathrm{AT}\left(\mathrm{AT}_{\text {sha }}\right)$ also takes the assessed wind effect into account; this index is assessed by the following formula:

$$
\mathrm{AT}_{\text {sha }}=T_{\text {air }}+0.33 e-0.70 V_{10}-4.00 .
$$

(iii) The outdoor $\mathrm{AT}\left(\mathrm{AT}_{\text {sun }}\right)$ expresses the sensation of a walking, clothed person fully exposed to all meteorological effects considered: air temperature and humidity, wind speed, and solar radiation; this index is assessed by the following formula:

$$
\mathrm{AT}_{\text {sun }}=T_{\text {air }}+0.348 e-0.70 V_{10}+0.70 \frac{Q_{g}}{\left(V_{10}+10\right)}-4.25,
$$

where " $e$ " is the water vapor pressure $(\mathrm{hPa})$ and " $\mathrm{Q}_{g}$ " is the heat-flow rate per unit area of body surface due to net extra radiation $\left(Q_{g}\right.$ is related to the mean radiant temperature). A detailed description of the assessment of $Q_{g}$ is reported in Steadman (1994). In this study the variable " $e$ " was calculated from the air temperature and the relative humidity using the following equation:

$$
e=\frac{\mathrm{RH}}{100} 6.105 \exp ^{\left(17.27\left(T_{\mathrm{air}} /\left(237.7+T_{\mathrm{air}}\right)\right)\right.} .
$$

The Universal Thermal Climate Index (UTCI) is a comprehensive model fitted to assess human thermal comfort in outdoor environments and represents the state-of-theart of outdoor thermal comfort indices [16]. UTCI is an equivalent temperature $\left({ }^{\circ} \mathrm{C}\right)$ based on the most recent scientific progress in human thermo-physiology, biophysics, and the heat exchange theory [25]. The UTCI represents the efforts of a group of over 45 scientists from 23 countries collaborating together within the COST action 730 [16]. The advanced multinode dynamic UTCI-Fiala mathematical model of human temperature regulation forms the basis of the UTCI. Furthermore, the UTCI also includes a sophisticated clothing model that defines in detail the effective clothing insulation and vapor resistance values for each of the thermophysiological model's body segments over a wide range of climatic conditions. A detailed description of the UTCI is reported in Jendritzky et al. [16]. In this study, the UTCI was assessed by using the UTCI software code "version a 0.002 ", freely available online (http://www.utci.org/). Currently, UTCI software uses fixed value for metabolic rate (activity level) and, depending on air temperature, also clothing insulation. The input parameters for the assessment of the UTCI that refers to a person walking at $4 \mathrm{~km} \mathrm{~h}^{-1}$ and generating $135 \mathrm{~W} \mathrm{~m}^{-2}$, are $T_{\text {air }}\left({ }^{\circ} \mathrm{C}\right), e(\mathrm{hPa}), V_{10}\left(\mathrm{~m} \mathrm{~s}^{-1}\right)$, and the mean radiant temperature $\left(T_{\mathrm{mrt}},{ }^{\circ} \mathrm{C}\right)$. The estimation of the $T_{\text {mrt }}$ was carried out separately by using the RayMan software version 2.0 [26]. One of the aims of the RayMan model is to calculate short- and long-wave radiation flux densities absorbed by people that can be transferred into a synthetic parameter, that is $T_{\mathrm{mrt}}$, defined as the uniform temperature of a hypothetical spherical surface surrounding a human (emissivity $\varepsilon=1$ ) which would result in the same net radiation energy exchange with the subject as the actual, complex radiative environment [26].

2.4. Statistical Analyses. A preliminary descriptive analysis was carried out of the characteristics of the daily mortality, air pollution, and main meteorological variables recorded in the two cities by urban and suburban weather stations during the warmest period of the year (May-October). In the following, a detailed description of daily summaries (daily average, maximum, and minimum) of thermal indices and air temperature indicators (defined as thermal indicators) was provided for both urban and suburban areas of the inland and coastal cities.

The analyses were organized in two main sections: (1) correlation analyses between the UTCI (rational index) versus direct indices and air temperature variables, assessed and measured by using urban and suburban meteorological stations; (2) investigation of relationships between daily mortality and the set of independent predictors represented 
by biometeorological (rational and direct indices) and meteorological (air temperature) indicators.

The first section of the study included linear regression analyses of daily average, maximum, and minimum UTCI in order to select direct daily biometeorological indices and air temperature variables. Statistical characteristics of the relationships were shown as slope coefficients of regressions and their relative $R$-squared (\%).

The second section was investigated through a time-series approach by using generalized additive models (GAMs) [27]. The GAM approach is useful for detecting the temporal modification of heat-related mortality based on different thermal indicators. GAMs are very flexible tools that allow for applying a wide variety of link functions on the dependent variable for taking any non-linear (smooth) effects of predictor variables into account. A Poisson link assumption was used in this study.

The GAM procedure was performed using $R$ software version 2.15.3 [28] and specifically the "mgcv" package [29]. GAM procedures were systematically used throughout the entire warmest period of the year to estimate the smoothed shape of exposure-response curves between total mortality and short-term changes of the set of daily average, maximum, and minimum independent biometeorological indices (UTCI, $\mathrm{AT}_{\text {sun }}, \mathrm{AT}_{\text {sha }}$, and $\mathrm{AT}_{\text {ind }}$ ) and air temperature $\left(T_{\text {air }}\right)$ variables, measured by using urban and suburban meteorological data. On the whole, 30 thermal indicators were identified for each city. The short-term change was calculated by averaging the daily biometeorological value or air temperature on a specific day together with the one calculated on the previous day $\left(\operatorname{lag}_{0-1}\right)$.

GAM models were controlled for typical air pollution concentrations and calendar factor confounders such as daylight hours (that represent a proxy parameter of the season), year (to check for annual variation in mortality), day of the week, public holidays, and summer population decrement.

The final model specification is based on the following equation:

$$
\ln (E(Y))=\beta_{0}+\beta_{1} \cdot X_{t}+\Sigma S_{i}\left(X_{i}\right),
$$

where $E(Y)$ is the estimated daily death count; $\beta_{0}$ is the intercept of the regression; $\beta_{1}$ is the coefficient (slope) for the thermal indicator $\left(X_{t}\right) ; S_{i}\left(X_{i}\right)$ denotes the smooth functions for the covariates (continuous: daylight hours and air pollutants; categorical: year, day of the week, public holidays, and summer population decrement).

Finally, in order to focus on the relationship between heat and mortality, the expected \% change of death due to a $1^{\circ} \mathrm{C}$ increase in air temperature (or thermal index temperature) was assessed by selecting the upper 25\% (75th percentile) of data based on each thermal indicator. The selection of the 75 th percentile was based on an empirical assessment in model fittings, where overall daily death counts generally showed a monotonic increase as thermal indicators increased.

2.5. Model Selection. Akaike Information Criterion (AIC) [30] was applied to the entire warmest period for the model-fitting criteria. AIC represents one of the most reliable methods for comparing different models, taking both descriptive accuracy and parsimony into account [31]. AIC has been widely applied in many statistical fields or research including time series model selection [32].

The AIC is defined as [33]

$$
\mathrm{AIC}_{i}=-2 \log L_{i}+2 V_{i},
$$

where $L_{i}$ represents the maximum likelihood for a candidate model $i$ and is determined by adjusting the $V_{i}$ free parameters in such a way as to maximize the probability of the candidate model generating the observed data [31].

Given a set of candidate models for the data, it is well known that the preferred model is the one with the minimum AIC value, which is the model with the lowest expected information loss.

However, because from a statistical point of view it is difficult to understand the importance of the AIC difference, $\Delta_{i}$ (AIC), between the best model (that is the model with the lowest AIC value), for example, and the next-best model (the second lowest AIC value), the AIC values obtained for each candidate model in this study have been transformed to the so-called Akaike weights, $w_{i}$ (AIC) [33]. For this reason, all the AIC differences with respect to the AIC of the best candidate model were calculated as follows:

$$
\Delta_{i}(\mathrm{AIC})=\mathrm{AIC}_{i}-\min (\mathrm{AIC}) .
$$

In the following, the Akaike weights were assessed by dividing the relative likelihood of a model $i$ by the sum of the likelihoods of all models $k$ as per the following equation:

$$
w_{i}(\mathrm{AIC})=\frac{\exp \left\{-(1 / 2) \Delta_{i}(\mathrm{AIC})\right\}}{\sum_{k=1}^{K} \exp \left\{-(1 / 2) \Delta_{k}(\mathrm{AIC})\right\}}
$$

In this way, the $w_{i}$ (AIC) can be interpreted as the probability that a hypothetical model is the best predictive model among the set of candidate models. The best model is the one that minimizes the Kullback-Leibler discrepancy, which is a measure of the distance between the probability density generated by the model and reality [31].

Akaike weights quantify conclusions based on AIC analyses and provide a straightforward interpretation of the AIC model comparison analysis.

\section{Results}

3.1. Descriptive Statistics of Mortality, Air Pollution, and Meteorological/Biometeorological Data. The characteristics of daily all-cause mortality of people aged $\geq 75$ years, mean air pollution concentrations, and meteorological variables recorded during the warmest period of the year (from May to October) are illustrated in Table 1.

Nonaccidental mortality data of the very elderly in the inland city was about twice as high as in the coastal city. Average $\mathrm{NO}_{2}, \mathrm{PM}_{10}$, and $\mathrm{CO}$ concentrations were significantly higher in the inland plain city than in the coastal one. On the other hand, the average $\mathrm{O}_{3}$ and especially $\mathrm{SO}_{2}$ showed the highest values in Livorno (Table 1). 
TABLE 1: Descriptive statistics for daily all-cause mortality of the very elderly (subjects $\geq 75$ years of age), air pollution, and meteorological parameters measured in urban and suburban areas of Florence and Livorno during the warmest period of the year (May-October) from 2006 to 2008. Mean, standard deviation (SD), and 10th, 75th, and 90th percentiles are shown.

\begin{tabular}{|c|c|c|c|c|c|c|c|c|c|}
\hline \multirow{2}{*}{ Variables } & \multirow{2}{*}{ Unit } & \multicolumn{4}{|c|}{ Inland plain city: Florence } & \multicolumn{4}{|c|}{ Coastal plain city: Livorno } \\
\hline & & Mean $( \pm \mathrm{SD})$ & 10 th & 75 th & 90th & Mean $( \pm \mathrm{SD})$ & 10th & 75th & 90th \\
\hline Mortality age $\geq 75$ years & $\mathrm{N}$ & $7.0( \pm 2.7)$ & 4 & 9 & 11 & $3.5( \pm 2.0)$ & 1 & 5 & 6 \\
\hline \multicolumn{10}{|l|}{ Air pollution } \\
\hline $\mathrm{SO}_{2}$ & $\mu \mathrm{g} \mathrm{m}^{-3}$ & $1.6( \pm 0.8)$ & 0.8 & 1.9 & 2.6 & $4.3( \pm 3.9)$ & 0.7 & 6.0 & 9.5 \\
\hline $\mathrm{NO}_{2}$ & $\mu \mathrm{g} \mathrm{m}^{-3}$ & $38.1( \pm 11.9)$ & 23.5 & 45.4 & 52.8 & $31.5( \pm 7.2)$ & 23.4 & 35.2 & 40.1 \\
\hline $\mathrm{CO}$ & $\mu \mathrm{g} \mathrm{m}^{-3}$ & $0.6( \pm 0.2)$ & 0.4 & 0.7 & 0.8 & $0.5( \pm 0.1)$ & 0.4 & 0.6 & 0.7 \\
\hline $\mathrm{O}_{3}$ & $\mu \mathrm{g} \mathrm{m}^{-3}$ & $70.1( \pm 20.4)$ & 42.9 & 83.3 & 95.7 & $76.0( \pm 18.0)$ & 52.1 & 87.9 & 99.4 \\
\hline $\mathrm{PM}_{10}$ & $\mu \mathrm{g} \mathrm{m}^{-3}$ & $30.6( \pm 11.3)$ & 18.6 & 35.3 & 43.4 & $27.7( \pm 7.9)$ & 19.4 & 31.2 & 37.4 \\
\hline \multicolumn{10}{|l|}{ Meteorology } \\
\hline \multicolumn{10}{|l|}{ Urban } \\
\hline$T_{\text {air }}$ & ${ }^{\circ} \mathrm{C}$ & $20.6( \pm 3.8)$ & 15.6 & 23.9 & 25.7 & $20.4( \pm 3.3)$ & 16.1 & 23.2 & 24.7 \\
\hline RH & $\%$ & $40.1( \pm 13.3)$ & 24.6 & 48.2 & 57.2 & $50.0( \pm 12.6)$ & 31.9 & 58.4 & 64.5 \\
\hline$V_{10}$ & $\mathrm{~m} \mathrm{~s}^{-1}$ & $1.7( \pm 0.7)$ & 0.9 & 1.9 & 2.2 & $2.0( \pm 0.6)$ & 1.1 & 2.3 & 2.9 \\
\hline$T_{\mathrm{mrt}}$ & ${ }^{\circ} \mathrm{C}$ & $21.1( \pm 5.9)$ & 12.7 & 25.7 & 28.1 & $21.2( \pm 5.1)$ & 13.8 & 25.1 & 26.9 \\
\hline \multicolumn{10}{|l|}{ Suburban } \\
\hline$T_{\text {air }}$ & ${ }^{\circ} \mathrm{C}$ & $21.9( \pm 4.2)$ & 16.4 & 25.5 & 27.8 & $22.6( \pm 3.6)$ & 17.9 & 25.4 & 27.3 \\
\hline RH & $\%$ & $42.4( \pm 13.2)$ & 25.8 & 50.0 & 59.6 & $61.1( \pm 16.6)$ & 39.4 & 72.4 & 84.1 \\
\hline$V_{10}$ & $\mathrm{~m} \mathrm{~s}^{-1}$ & $3.1( \pm 0.7)$ & 2.2 & 3.5 & 3.9 & $5.5( \pm 2.5)$ & 3.5 & 5.8 & 8.3 \\
\hline$T_{\mathrm{mrt}}$ & ${ }^{\circ} \mathrm{C}$ & $22.5( \pm 6.3)$ & 13.6 & 27.3 & 30.0 & $23.2( \pm 5.2)$ & 16.0 & 26.9 & 29.1 \\
\hline
\end{tabular}

$T_{\text {air }}$ : environmental temperature; RH: relative humidity; $V_{10}: 10 \mathrm{~m}$ high horizontal wind speed; $T_{\text {mrt }}$ : mean radiant temperature.

Both the inland and coastal cities showed higher daily mean $T_{\text {air }}$ in the suburbs than in the urban areas. Moreover, the $T_{\text {air }}$ in the urban area of the inland plain city was slightly higher than the $T_{\text {air }}$ in the coastal city. Conversely, the opposite situation was observed when the suburbs were considered. The $T_{\text {air }}$ range over the warmest period of the year (differences between 90th and 10th percentiles of $T_{\text {air }}$ data) was not as wide in urban areas and coastal city as in the suburbs and inland city. As expected, mean $\mathrm{RH}$ and $V_{10}$ were always higher in the coastal city than in the inland one, with the highest values in the suburbs. The mean $T_{\text {mrt }}$ was lower in the urban than suburban areas, with the highest mean values on the coast. Moreover, both inland and coastal cities showed wider $T_{\text {mrt }}$ ranges than $T_{\text {air }}$ ranges (Table 1 ).

Thermal indices and air temperature indicators in the coastal city generally showed higher mean values than in the inland city, with several exceptions, especially when daily maximum values in both urban and suburban areas (Table 2) were taken into account. More specifically, when the maximum $T_{\text {air }}$ was considered, the lowest values were observed in the coastal city.

The daily mean average, minimum, and maximum thermal indicators measured in urban areas generally showed lower values than in the suburbs, with the only exception for the daily maximum UTCI in both cities and the maximum $\mathrm{AT}_{\text {sun }}$ in the coastal city, which recorded the opposite situation. Furthermore, thermal indicators in the suburbs of both Florence and Livorno always showed wider thermal ranges (differences between 90th and 10th percentiles of data) than those observed in urban areas (Table 2).

The $\mathrm{AT}_{\text {sun }}$ always disclosed the highest daily average, minimum, and maximum values among all indicators. On the other hand, UTCI and $T_{\text {air }}$ often evidenced the lowest daily mean average and minimum values. The $\mathrm{AT}_{\text {sha }}$, which also takes into consideration the cooling effect of wind, always showed the lowest values among the direct indices. When daily maximum values were considered, both $\mathrm{AT}_{\text {sun }}$ and UTCI revealed the highest values when compared with the other indicators, thanks to the solar radiation contribution (Table 2).

3.2. Rational Index (UTCI) versus Direct Indices and Air Temperature Variables. The comparison between daily average, minimum, and maximum UTCI and direct bivariate/multivariate indices or air temperatures (Table 3 ) revealed that both $\mathrm{AT}_{\text {sun }}$ and $\mathrm{AT}_{\text {sha }}$ showed the highest correlation coefficients in both urban and suburban areas of the inland and coastal cities. On the other hand, both $\mathrm{AT}_{\text {ind }}$ and $T_{\text {air }}$ showed the lowest $R^{2}$ coefficients.

Generally, $\mathrm{AT}_{\text {sun }}$ and $\mathrm{AT}_{\text {sha }}$ revealed that were the highest mean correlations when daily minimum values were considered, slightly higher than the correlations when daily average values were used. An opposite situation was observed when $\mathrm{AT}_{\text {ind }}$ and $\mathrm{T}_{\mathrm{air}}$ were considered, whereas daily maximum values always showed the lowest correlation coefficients.

When daily average indicator values were considered, there was a progressive decrease of the mean $R^{2}$ coefficients (averaged from all stations), with the highest values observed for $\mathrm{AT}_{\text {sun }}(96.50 \%)$ followed by $\mathrm{AT}_{\text {sha }}$ (96.46\%), $\mathrm{AT}_{\text {ind }}$ (93.34\%), and $T_{\text {air }}(93.19 \%)$ (Table 3$)$. When daily minimum values were considered, the highest mean $R^{2}$ coefficient was observed for $\mathrm{AT}_{\text {sha }}(96.67 \%)$, slightly higher than the $\mathrm{AT}_{\text {sun }}$ (96.56\%) value. When daily maximums were considered, $T_{\text {air }}$ often showed a better fit than $\mathrm{AT}_{\text {ind }}$ and $\mathrm{AT}_{\text {sha. However, }}$ 
TABLE 2: Descriptive statistics of daily thermal indices and air temperature indicators assessed and measured in urban and suburban areas of Florence and Livorno during the warmest period of the year (May-October) from 2006 to 2008. Mean, standard deviation (SD), and 10th, 75th, and 90th percentiles are shown.

\begin{tabular}{|c|c|c|c|c|c|c|c|c|}
\hline \multirow{2}{*}{$\begin{array}{l}\text { Daily thermal indices and air } \\
\text { temperature indicators }\left({ }^{\circ} \mathrm{C}\right)\end{array}$} & \multicolumn{4}{|c|}{ Inland plain city: Florence } & \multicolumn{4}{|c|}{ Coastal plain city: Livorno } \\
\hline & Mean $( \pm \mathrm{SD})$ & 10th & 75th & 90th & Mean $( \pm \mathrm{SD})$ & 10th & 75th & 90th \\
\hline \multicolumn{9}{|l|}{ Urban } \\
\hline \multicolumn{9}{|l|}{ Average } \\
\hline UTCI & $20.6( \pm 4.3)$ & 15.0 & 24.0 & 26.0 & $20.8( \pm 3.9)$ & 15.7 & 24.0 & 25.5 \\
\hline $\mathrm{AT}_{\text {sun }}$ & $24.6( \pm 5.3)$ & 17.6 & 28.7 & 31.5 & $25.2( \pm 5.1)$ & 18.6 & 29.2 & 31.6 \\
\hline $\mathrm{AT}_{\text {sha }}$ & $20.7( \pm 4.5)$ & 14.8 & 24.3 & 26.6 & $21.1( \pm 4.2)$ & 15.6 & 24.6 & 26.4 \\
\hline $\mathrm{AT}_{\text {ind }}$ & $21.3( \pm 4.2)$ & 15.8 & 24.4 & 26.7 & $21.7( \pm 4.0)$ & 16.5 & 25.0 & 26.7 \\
\hline$T_{\text {air }}$ & $20.6( \pm 3.8)$ & 15.6 & 23.9 & 25.7 & $20.4( \pm 3.3)$ & 16.1 & 23.3 & 24.7 \\
\hline \multicolumn{9}{|l|}{ Minimum } \\
\hline UTCI & $13.7( \pm 3.7)$ & 9.0 & 16.5 & 18.1 & $14.6( \pm 3.6)$ & 10.1 & 17.3 & 18.8 \\
\hline $\mathrm{AT}_{\text {sun }}$ & $18.2( \pm 4.8)$ & 11.7 & 21.8 & 23.9 & $19.3( \pm 4.8)$ & 13.1 & 23.0 & 25.1 \\
\hline $\mathrm{AT}_{\text {sha }}$ & $16.0( \pm 4.1)$ & 10.5 & 19.1 & 21.1 & $17.1( \pm 4.1)$ & 11.8 & 20.2 & 22.0 \\
\hline $\mathrm{AT}_{\text {ind }}$ & $16.8( \pm 3.9)$ & 11.5 & 19.8 & 21.6 & $17.9( \pm 3.9)$ & 12.9 & 20.8 & 22.5 \\
\hline$T_{\text {air }}$ & $15.8( \pm 3.3)$ & 11.3 & 18.3 & 20.0 & $16.7( \pm 3.2)$ & 12.5 & 19.1 & 20.7 \\
\hline \multicolumn{9}{|l|}{ Maximum } \\
\hline UTCI & $30.9( \pm 5.1)$ & 23.7 & 34.9 & 37.4 & $30.8( \pm 4.2)$ & 25.3 & 33.9 & 35.9 \\
\hline $\mathrm{AT}_{\text {sun }}$ & $33.1( \pm 6.2)$ & 24.7 & 38.0 & 41.0 & $34.4( \pm 5.9)$ & 26.8 & 39.2 & 41.6 \\
\hline $\mathrm{AT}_{\text {sha }}$ & $25.7( \pm 5.2)$ & 18.9 & 29.9 & 32.7 & $25.6( \pm 4.5)$ & 20.0 & 29.1 & 31.6 \\
\hline $\mathrm{AT}_{\text {ind }}$ & $25.9( \pm 4.7)$ & 19.7 & 29.7 & 32.1 & $25.9( \pm 4.3)$ & 20.7 & 29.4 & 31.5 \\
\hline$T_{\text {air }}$ & $26.0( \pm 4.7)$ & 20.1 & 29.9 & 32.4 & $24.9( \pm 3.7)$ & 20.7 & 28.1 & 29.9 \\
\hline \multicolumn{9}{|l|}{ Suburban } \\
\hline \multicolumn{9}{|l|}{ Average } \\
\hline UTCI & $21.2( \pm 5.1)$ & 14.6 & 25.3 & 28.0 & $21.1( \pm 5.8)$ & 13.8 & 25.2 & 28.0 \\
\hline $\mathrm{AT}_{\text {sun }}$ & $25.9( \pm 6.0)$ & 18.1 & 30.5 & 33.7 & $27.7( \pm 6.8)$ & 19.2 & 32.5 & 36.0 \\
\hline $\mathrm{AT}_{\text {sha }}$ & $22.0( \pm 5.1)$ & 15.4 & 26.0 & 28.9 & $23.4( \pm 5.6)$ & 16.4 & 27.6 & 30.3 \\
\hline $\mathrm{AT}_{\text {ind }}$ & $23.0( \pm 4.7)$ & 16.9 & 26.7 & 29.3 & $25.6( \pm 5.2)$ & 18.9 & 29.3 & 32.1 \\
\hline$T_{\text {air }}$ & $21.9( \pm 4.2)$ & 16.4 & 25.5 & 27.8 & $22.6( \pm 3.6)$ & 17.9 & 25.4 & 27.3 \\
\hline \multicolumn{9}{|l|}{ Minimum } \\
\hline UTCI & $13.8( \pm 4.5)$ & 8.2 & 17.2 & 19.4 & $14.8( \pm 6.6)$ & 6.6 & 19.6 & 22.6 \\
\hline $\mathrm{AT}_{\text {sun }}$ & $19.2( \pm 5.3)$ & 12.1 & 23.2 & 26.0 & $22.3( \pm 6.8)$ & 13.8 & 27.0 & 30.1 \\
\hline $\mathrm{AT}_{\text {sha }}$ & $16.8( \pm 4.7)$ & 10.7 & 20.3 & 22.8 & $19.6( \pm 5.8)$ & 12.3 & 23.7 & 26.8 \\
\hline $\mathrm{AT}_{\text {ind }}$ & $18.1( \pm 4.4)$ & 12.4 & 21.3 & 23.9 & $22.4( \pm 5.2)$ & 15.6 & 25.9 & 29.0 \\
\hline$T_{\text {air }}$ & $16.6( \pm 3.7)$ & 11.7 & 19.3 & 21.4 & $19.8( \pm 3.8)$ & 14.7 & 22.8 & 24.8 \\
\hline \multicolumn{9}{|l|}{ Maximum } \\
\hline UTCI & $30.7( \pm 6.0)$ & 22.4 & 35.3 & 37.9 & $28.5( \pm 5.4)$ & 21.6 & 32.4 & 34.7 \\
\hline $\mathrm{AT}_{\text {sun }}$ & $33.5( \pm 6.8)$ & 24.1 & 38.7 & 41.9 & $34.3( \pm 7.2)$ & 24.8 & 39.8 & 43.2 \\
\hline $\mathrm{AT}_{\text {sha }}$ & $26.8( \pm 5.7)$ & 19.3 & 31.5 & 34.3 & $27.0( \pm 5.4)$ & 20.0 & 30.9 & 33.7 \\
\hline $\mathrm{AT}_{\text {ind }}$ & $27.6( \pm 5.3)$ & 20.7 & 31.9 & 34.6 & $28.4( \pm 5.2)$ & 21.6 & 32.4 & 34.9 \\
\hline$T_{\text {air }}$ & $27.4( \pm 5.1)$ & 20.6 & 31.5 & 34.0 & $25.1( \pm 3.5)$ & 20.6 & 27.7 & 29.9 \\
\hline
\end{tabular}

UTCI: Universal Thermal Climate Index; $\mathrm{AT}_{\text {sun }}$ : apparent temperature assessed outdoors also taking into consideration the solar radiation contribution; $\mathrm{AT}_{\text {sha }}$ : apparent temperature assessed outdoors in the shade; $\mathrm{AT}_{\text {ind }}$ apparent temperature assessed in indoor conditions; $T_{\text {air }}$ : environmental temperature.

$T_{\text {air }}$ always showed the worst mean slope coefficients of regression lines, with the lowest values (from 0.50 to 0.56 ) observed in the suburb of the coastal city (Table 3). This indicates that UTCI and $T_{\text {air }}$ change at different rates within various ranges of ambient conditions, especially in suburban areas.

Conversely, the best mean slope coefficients were always observed when $\mathrm{AT}_{\text {sun }}$ was considered: mean slope 1.00, 
TABLE 3: Correlation analyses between daily average, minimum, and maximum UTCI versus direct thermal indices and air temperature indicators in urban and suburban areas of Florence and Livorno during the warmest period of the year (May-October) from 2006 to 2008.

\begin{tabular}{|c|c|c|c|c|c|}
\hline \multirow{3}{*}{$\begin{array}{l}\text { Daily thermal indices } \\
\text { and air temperature } \\
\text { indicators }\end{array}$} & \multicolumn{2}{|c|}{ Inland plain city: Florence } & \multicolumn{2}{|c|}{ Coastal plain city: Livorno } & \multirow{3}{*}{$\begin{array}{c}\text { Mean values from } \\
\text { all stations } \\
\text { Slope; } R^{2}(\%)\end{array}$} \\
\hline & $\begin{array}{c}\text { Urban } \\
(\text { missing data }=0 \%)\end{array}$ & $\begin{array}{c}\text { Suburban } \\
(\text { missing data }=0.4 \%)\end{array}$ & $\begin{array}{c}\text { Urban } \\
(\text { missing data }=0 \%)\end{array}$ & $\begin{array}{c}\text { Suburban } \\
(\text { missing data }=0 \%)\end{array}$ & \\
\hline & Slope; $R^{2}(\%)$ & Slope; $R^{2}(\%)$ & Slope; $R^{2}(\%)$ & Slope; $R^{2}(\%)$ & \\
\hline \multicolumn{6}{|l|}{ Average } \\
\hline $\mathrm{AT}_{\text {sun }}$ & $1.193 ; 96.22$ & $1.121 ; 96.85$ & $1.284 ; 96.41$ & $1.114 ; 96.51$ & $1.178 ; 96.50$ \\
\hline $\mathrm{AT}_{\text {sha }}$ & $1.029 ; 96.27$ & $0.971 ; 96.76$ & $1.073 ; 96.10$ & $0.926 ; 96.71$ & $1.000 ; 96.46$ \\
\hline $\mathrm{AT}_{\text {ind }}$ & $0.949 ; 95.00$ & $0.891 ; 94.61$ & $1.008 ; 94.80$ & $0.821 ; 88.95$ & $0.917 ; 93.34$ \\
\hline$T_{\text {air }}$ & $0.865 ; 96.07$ & $0.796 ; 94.82$ & $0.827 ; 94.62$ & $0.562 ; 87.24$ & $0.763 ; 93.19$ \\
\hline \multicolumn{6}{|l|}{ Minimum } \\
\hline $\mathrm{AT}_{\text {sun }}$ & $1.280 ; 97.32$ & $1.160 ; 95.26$ & $1.293 ; 97.43$ & $0.992 ; 96.21$ & $1.192 ; 96.56$ \\
\hline $\mathrm{AT}_{\text {sha }}$ & $1.113 ; 97.41$ & $1.014 ; 94.82$ & $1.138 ; 97.99$ & $0.848 ; 96.46$ & $1.028 ; 96.67$ \\
\hline $\mathrm{AT}_{\text {ind }}$ & $1.038 ; 96.07$ & $0.935 ; 90.50$ & $1.070 ; 96.11$ & $0.711 ; 83.53$ & $0.939 ; 91.55$ \\
\hline$T_{\text {air }}$ & $0.866 ; 93.50$ & $0.764 ; 87.95$ & $0.854 ; 92.60$ & $0.502 ; 79.27$ & $0.747 ; 88.33$ \\
\hline \multicolumn{6}{|l|}{ Maximum } \\
\hline $\mathrm{AT}_{\text {sun }}$ & $1.110 ; 93.61$ & $1.050 ; 94.03$ & $1.263 ; 91.80$ & $1.176 ; 89.51$ & $1.150 ; 92.24$ \\
\hline $\mathrm{AT}_{\text {sha }}$ & $0.951 ; 91.06$ & $0.909 ; 92.49$ & $0.960 ; 85.96$ & $0.869 ; 83.11$ & $0.922 ; 88.16$ \\
\hline $\mathrm{AT}_{\text {ind }}$ & $0.863 ; 89.77$ & $0.830 ; 90.59$ & $0.891 ; 84.15$ & $0.792 ; 76.15$ & $0.844 ; 85.17$ \\
\hline$T_{\text {air }}$ & $0.881 ; 93.58$ & $0.824 ; 93.59$ & $0.801 ; 87.70$ & $0.549 ; 76.63$ & $0.764 ; 87.88$ \\
\hline
\end{tabular}

UTCI: Universal Thermal Climate Index; $\mathrm{AT}_{\text {sun }}$ : apparent temperature assessed outdoors also taking into consideration the solar radiation contribution; $\mathrm{AT}_{\text {sha }}$ : apparent temperature assessed outdoors in the shade; $\mathrm{AT}_{\text {ind }}$ : apparent temperature assessed in indoor conditions; $T_{\text {air }}$ : environmental temperature.

1.03 , and 0.92 for average, minimum, and maximum values, respectively.

\subsection{Relationships between Mortality and the Set of Biometeoro-} logical Indices and Air Temperature Indicators. The smoothing plots of short-term exposure-response curves during the warmest period of the year (May-October) clearly illustrate the relationships between mortality and the set of independent biometeorological (rational and direct indices) and meteorological $\left(T_{\text {air }}\right)$ indicators. The results are reported in Figures 1, 2, and 3 for the average, maximum, and minimum values, respectively. The "U-shaped" relationships between short-term effects $\left(\operatorname{lag}_{0-1}\right)$ of each daily average (Figure 1 ), maximum (Figure 2), and minimum (Figure 3) thermal indicator and mortality were identified in both urban and suburban areas of the inland plain city. Conversely, prevalent "J-shaped" relationships were identified in the coastal city. In this case, steeper right-hand slope curves (heat effects) were observed which also reached higher relative risks than the inland city.

When the same geographical location was considered, similar exposure-response curves between total mortality and different thermal indicators were usually observed, even if the range of indicators varied depending on specific indicator characteristics. No substantial differences were observed in the curves between urban and suburban areas in the inland city (Figures 1,2, and 3). On the other hand, different patterns were found between the urban and suburban curves in the coastal city: steeper right-hand slope curves were observed in the urban area (Figures 1, 2, and 3).
The urban daily average $\mathrm{AT}_{\text {sun }}$ was selected as the best predictive model for the inland plain city. This model showed a high probability (almost 50\%) of being the best model among the set of 30 candidate models (Table 4). Furthermore, a significant expected \% change in deaths (5.6\%, CI: 0.5-10.7, $P<0.05)$ was evidenced. In addition, other models, such as the urban daily average $\mathrm{AT}_{\text {sha }}$ and maximum UTCI and the urban and suburban minimum $\mathrm{AT}_{\text {sun }}$, also showed good model-fits, displaying $w_{i}$ (AIC) superior to $5 \%$. However, only the urban daily minimum $\mathrm{AT}_{\text {sun }}$ still confirmed a significant expected \% change of death (6.1\%, CI: 1.2-11.0, $P<0.05)$ (Table 4), whereas less model-fits often included the $\mathrm{AT}_{\text {ind }}$.

The urban daily minimum $\mathrm{AT}_{\text {sha }}$ was selected as the best predictive model for the coastal city (Table 4 ). In this case, the probability that this model was the best among all candidate models was almost $60 \%$. A very high significant expected \% change in deaths was also observed (10.3\%, CI: 4.0-16.6, $P<0.01$ ). Furthermore, an elevated probability (21\%) of being the second best model among the others was associated with the suburban daily average $\mathrm{AT}_{\text {ind }}$, even confirming a significant $\%$ change in deaths (Table 4 ). In addition, the urban minimum $\mathrm{AT}_{\text {sun }}$ and the suburban $\mathrm{AT}_{\text {ind }}$ also revealed good model-fits, showing $w_{i}$ (AIC) of $8 \%$. Less predictive model-fits prevalently included daily maximum thermal indicators.

\section{Discussion}

This research provides a substantial contribution to previous studies referred to in identifying the most effective 
TABLE 4: Summary of predictive model fits and expected \% change in deaths due to a $1^{\circ} \mathrm{C}$ increase in the thermal predictor over the 75 th percentile based on each thermal indicator. ${ }^{*} P<0.05 ;{ }^{* *} P<0.01$.

\begin{tabular}{|c|c|c|c|c|c|c|c|}
\hline \multicolumn{4}{|c|}{ Inland plain city: Florence } & \multicolumn{4}{|c|}{ Coastal plain city: Livorno } \\
\hline Indicators & AIC & $w_{i}(\mathrm{AIC})$ & $\%$ change & Indicators & AIC & $w_{i}(\mathrm{AIC})$ & $\%$ change \\
\hline$\overline{\text { Ave_urb_AT }}$ sun & 663.3 & 0.48 & $5.6(0.5 ; 10.7)^{*}$ & Min_urb_AT $T_{\text {sha }}$ & 587.7 & 0.58 & $10.3(4.0 ; 16.6)^{* *}$ \\
\hline Ave_urb_AT $\mathrm{T}_{\text {sha }}$ & 665.1 & 0.19 & $4.8(-1.1 ; 10.7)$ & Ave_sub_AT $T_{\text {ind }}$ & 589.7 & 0.21 & $4.7(0.2 ; 9.2)^{*}$ \\
\hline Max_urb_UTCI & 666.2 & 0.11 & $4.9(-1.0 ; 10.8)$ & Min_urb_AT $T_{\text {sun }}$ & 591.7 & 0.08 & $6.8(1.7 ; 11.9)^{* *}$ \\
\hline Min_urb_AT ${ }_{\text {sun }}$ & 667.2 & 0.07 & $6.1(1.2 ; 11.0)^{*}$ & Min_sub_AT $T_{\text {ind }}$ & 591.7 & 0.08 & $4.8(0.7 ; 8.9)^{*}$ \\
\hline Min_sub_AT $T_{\text {sun }}$ & 667.9 & 0.05 & $3.8(-0.3 ; 7.9)$ & Max_sub_AT ind & 594.7 & 0.02 & $4.5(-0.4 ; 9.4)$ \\
\hline Min_urb_UTCI & 668.2 & 0.04 & $9.2(2.1 ; 16.3)^{*}$ & Ave_sub_AT sun & 596.0 & 0.01 & $3.3(-0.4 ; 7)$ \\
\hline Ave_urb_ $T_{\text {air }}$ & 669.2 & 0.03 & $3.8(-3.8 ; 11.4)$ & Ave_sub_AT ${ }_{\text {sha }}$ & 596.5 & 0.01 & $4.7(0.1 ; 9.4)^{*}$ \\
\hline Max_urb_AT ${ }_{\text {ind }}$ & 671.0 & 0.01 & $2.7(-2.8 ; 8.2)$ & Min_sub_AT ${ }_{\text {sun }}$ & 597.5 & 0.00 & $4.1(0.8 ; 7.4)^{*}$ \\
\hline Max_sub_UTCI & 671.5 & 0.01 & $4.3(-0.6 ; 9.2)$ & Max_sub_UTCI & 599.0 & 0.00 & $6.5(1.4 ; 11.6)^{*}$ \\
\hline Min_urb_AT $\mathrm{T}_{\text {ind }}$ & 672.7 & 0.00 & $8.0(1.9 ; 14.1)^{*}$ & Min_urb_AT $T_{\text {ind }}$ & 600.2 & 0.00 & $9.6(3.3 ; 15.9)^{* *}$ \\
\hline Max_urb_ $T_{\text {air }}$ & 673.2 & 0.00 & $1.3(-4.8 ; 7.4)$ & Min_sub_UTCI & 602.4 & 0.00 & $4.9(0.8 ; 9.0)^{*}$ \\
\hline Max_sub_T $T_{\text {air }}$ & 673.5 & 0.00 & $2.3(-3.2 ; 7.8)$ & Max_sub_AT sun & 603.4 & 0.00 & $2.6(-1.1 ; 6.3)$ \\
\hline Ave_sub_$T_{\text {air }}$ & 674.0 & 0.00 & $1.5(-5.4 ; 8.4)$ & Ave_urb_AT ind & 604.4 & 0.00 & $8.5(1.4 ; 15.6)^{*}$ \\
\hline Max_urb_AT & 674.8 & 0.00 & $3.2(-2.1 ; 8.5)$ & Min_sub_AT $T_{\text {sha }}$ & 604.9 & 0.00 & $4.7(0.6 ; 8.8)^{*}$ \\
\hline Ave_sub_AT ind & 675.7 & 0.00 & $4.0(-1.1 ; 9.1)$ & Max_sub_AT sha & 605.6 & 0.00 & $3.6(-1.3 ; 8.5)$ \\
\hline Max_sub_AT ${ }_{\text {sha }}$ & 676.1 & 0.00 & $4.4(-0.5 ; 9.3)$ & Min_urb_UTCI & 606.7 & 0.00 & $11.7(4.1 ; 19.3)^{* *}$ \\
\hline Max_urb_AT $T_{\text {sun }}$ & 676.4 & 0.00 & $2.8(-1.9 ; 7.5)$ & Ave_sub_ $T_{\text {air }}$ & 607.7 & 0.00 & $8.4(0.1 ; 16.8)^{*}$ \\
\hline Min_sub_UTCI & 677.9 & 0.00 & $3.2(-1.9 ; 8.3)$ & Max_urb_AT $T_{\text {ind }}$ & 609.1 & 0.00 & $11.7(3.9 ; 19.5)^{* *}$ \\
\hline Min_sub_AT ${ }_{\text {sha }}$ & 678.4 & 0.00 & $5.3(0.4 ; 10.2)^{*}$ & Ave_sub_UTCI & 613.8 & 0.00 & $5.5(1.0 ; 10.0)^{*}$ \\
\hline Ave_sub_UTCI & 679.3 & 0.00 & $3.3(-2.2 ; 8.8)$ & Ave_urb_UTCI & 617.6 & 0.00 & $11.3(2.7 ; 19.9)^{* *}$ \\
\hline Min_urb_t $T_{\text {air }}$ & 679.8 & 0.00 & $10.2(1.5 ; 16.7)^{*}$ & Min_urb_ $T_{\text {air }}$ & 617.8 & 0.00 & $9.2(0.4 ; 18.0)^{*}$ \\
\hline Ave_sub_AT ${ }_{\text {sha }}$ & 680.0 & 0.00 & $3.0(-1.9 ; 7.9)$ & Ave_urb_AT $T_{\text {sha }}$ & 620.6 & 0.00 & $6.4(-0.5 ; 13.3)$ \\
\hline Ave_sub_AT $T_{\text {sun }}$ & 680.4 & 0.00 & $3.7(-0.4 ; 7.8)$ & Min_sub_ $T_{\text {air }}$ & 621.3 & 0.00 & $7.2(-0.4 ; 14.8)$ \\
\hline Min_urb_AT ${ }_{\text {sha }}$ & 680.9 & 0.00 & $7.5(1.6 ; 13.4)^{*}$ & Ave_urb_AT ${ }_{\text {sun }}$ & 621.8 & 0.00 & $6.5(1.0 ; 12.0)^{*}$ \\
\hline Max_sub_AT sun & 681.8 & 0.00 & $4.3(0.2 ; 8.4)^{*}$ & Max_urb_AT sun & 622.7 & 0.00 & $6.2(0.7 ; 11.7)^{*}$ \\
\hline Max_sub_AT ind & 685.0 & 0.00 & $4.4(-0.5 ; 9.3)$ & Max_sub_T $T_{\text {air }}$ & 623.2 & 0.00 & $2.8(-4.3 ; 9.9)$ \\
\hline Ave_urb_UTCI & 691.8 & 0.00 & $5.6(-1.1 ; 12.3)$ & Ave_urb_ $T_{\text {air }}$ & 631.4 & 0.00 & $10.2(0.8 ; 19.6)^{*}$ \\
\hline Min_sub_T $T_{\text {air }}$ & 702.3 & 0.00 & $7.1(0.6 ; 13.6)^{*}$ & Max_urb_UTCI & 639.2 & 0.00 & $9.3(1.1 ; 17.5)^{*}$ \\
\hline Min_sub_AT $\mathrm{T}_{\text {ind }}$ & 704.8 & 0.00 & $5.3(0.2 ; 10.4)^{*}$ & Max_urb_ $T_{\text {air }}$ & 641.5 & 0.00 & $4.8(-3.6 ; 13.2)$ \\
\hline Ave_urb_AT ${ }_{\text {ind }}$ & 713.8 & 0.00 & $4.5(-1.0 ; 10.0)$ & Max_urb_AT $T_{\text {sha }}$ & 642.1 & 0.00 & $7.2(0.3 ; 14.1)^{*}$ \\
\hline
\end{tabular}

AIC: Akaike's Information Criterion; $w_{i}$ (AIC): Akaike weights; Max: maximum; Min: minimum; Ave: average; urb: urban; sub: suburban; UTCI: Universal Thermal Climate Index; $\mathrm{AT}_{\text {sun }}$ : apparent temperature assessed outdoors also taking into consideration the solar radiation contribution; $\mathrm{AT}_{\text {sha }}$ : apparent temperature assessed outdoors in the shade; $\mathrm{AT}_{\text {ind }}$ : apparent temperature assessed in indoor conditions; $T_{\text {air: }}$ environmental temperature.

thermal/air temperature predictor of heat-related mortality in different geographical contexts.

A large amount of environmental epidemiological studies carried out worldwide over recent decades applied different thermal indicators by using a predefined relation of changed daily temporal summaries (daily average, maximum, or minimum values), which further complicated the explanations and comparisons of the results.

Most of studies generally used single meteorological parameters, in particular air temperature, or simple, mainly two-parameter, direct indices [3,6-11] as environmental predictors of mortality. Moreover, recent progress in the field of outdoor thermal comfort assessment led to the development of the UTCI [16], which represents a universal solution to the problem of characterizing the human thermal environment based on the most advanced multinode model of human thermoregulation coupled with a state-of-the-art clothing model. However, at the present time, no consistent information is available regarding the smoothed shape of exposure-response curves between mortality and different biometeorological (direct and rational indices) and air temperature indicators.

Currently, what is clearly known and generally recognized is the short-term impact of heat on mortality with the greatest effect on the elderly [9]. In a recent study carried out in the same geographical context as this study, the authors also evidenced a greater short-term impact of heat on the very elderly population (people aged $\geq 75$ ) [3]. This is the reason why this study directly focused on the very elderly. follows.

The main findings of this study can be summarized as

(i) Simple, direct four- and three-parameter indices $\left(\mathrm{AT}_{\text {sun }}\right.$ and $\left.\mathrm{AT}_{\text {sha }}\right)$ showed the highest correlations 

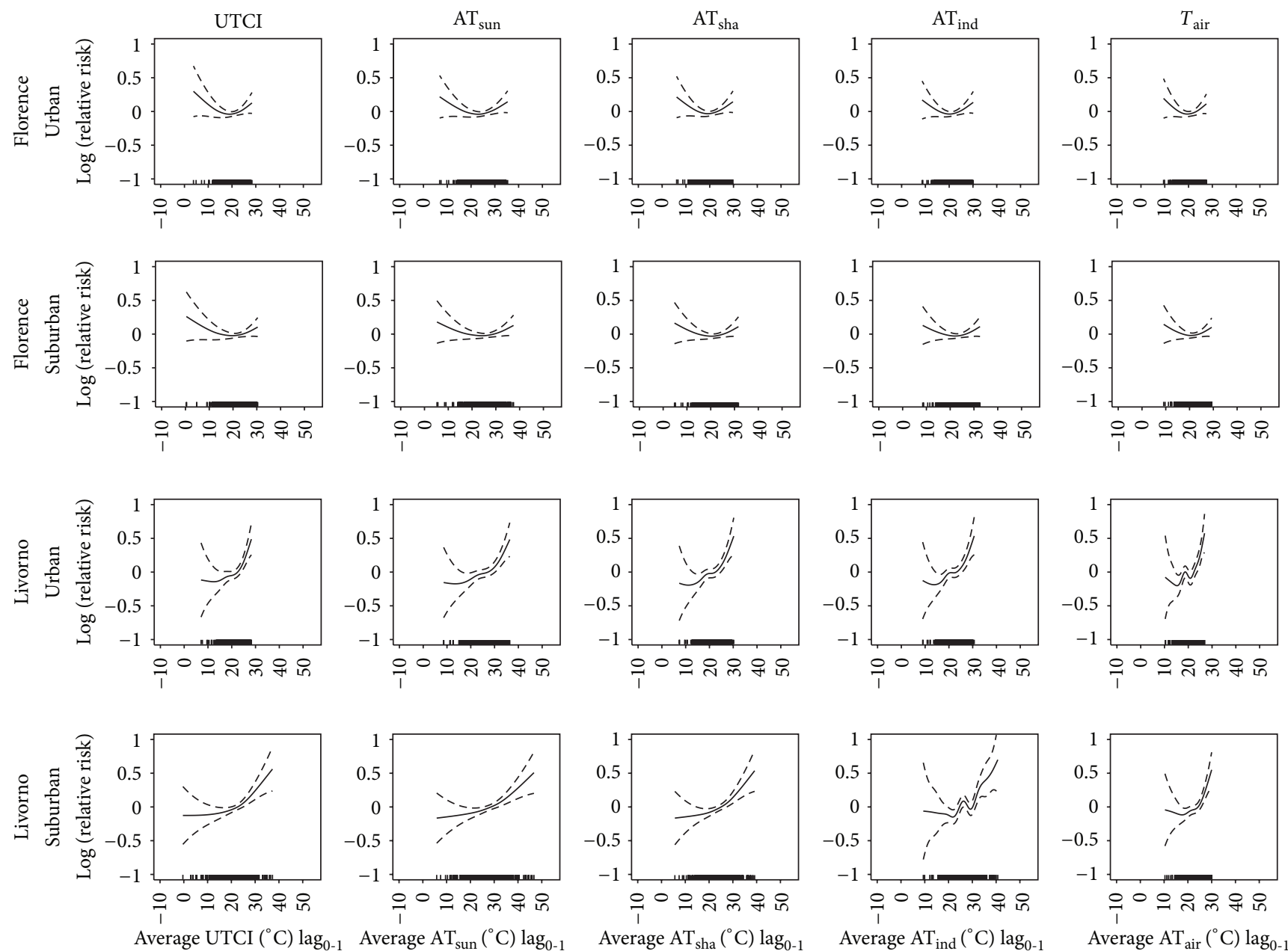

FIGURE 1: Relationships between daily average thermal predictors $\left(\operatorname{lag}_{0-1}\right)\left({ }^{\circ} \mathrm{C}\right)$ and mortality of the very elderly (subjects $\geq 75$ years of age) in an inland city (Florence) and coastal-plain city (Livorno). Relationships estimated by using urban and suburban meteorological data for the period 2006-2008 (May-October). UTCI: Universal Thermal Climate Index; $\mathrm{AT}_{\text {sun }}$ : apparent temperature assessed outdoors also taking the solar radiation contribution into account; $\mathrm{AT}_{\text {sha }}$ : apparent temperature assessed outdoors in the shade; $\mathrm{AT}_{\text {ind }}$ : apparent temperature assessed in indoor conditions; $T_{\text {air }}$ : environmental temperature. Analyses were controlled for air pollution concentrations, daylight hours, year, day of the week, public holidays, and summer population decrement.

with UTCI. Conversely, the direct two-parameter index $\left(\mathrm{AT}_{\text {ind }}\right)$ and the single meteorological parameter $\left(T_{\text {air }}\right)$ showed the lowest correlations.

(ii) "U-" and "J-shaped" relationships between shortterm effects of each daily thermal indicator and mortality were identified in the inland and coastal plain cities, respectively. Furthermore, when the same geographical location was considered, similar exposureresponse curves were observed between total mortality and different thermal indicators in both urban and suburban areas of the inland plain city. On the other hand, steeper right-hand slope curves (heat effects) were observed in the urban area of the coastal city than in the suburban ones.

(iii) Urban daily average $\mathrm{AT}_{\text {sun }}$ and minimum $\mathrm{AT}_{\text {sha }}$ showed the lowest AIC values and the highest probability (almost 50\% for the average $\mathrm{AT}_{\text {sun }}$ and $60 \%$ for the minimum $\mathrm{AT}_{\text {sha }}$ ) of being the best model among the set of 30 candidate models. For these reasons, these thermal indicators were selected as the best predictors of heat-related all-cause mortality in the very elderly for the inland (urban daily average $\mathrm{AT}_{\text {sun }}$ ) and coastal (urban daily minimum $\mathrm{AT}_{\text {sha }}$ ) cities, also revealing significant expected $\%$ change of death due to a $1^{\circ} \mathrm{C}$ increase above the 75 th percentile. On the other hand, less predictive model-fits often included the $\mathrm{AT}_{\text {ind }}$ for the inland city and prevalently involved daily maximum indicators for the coastal city.

4.1. UTCI versus Direct Indices and Air Temperature Variables. As expected, simple direct indices which also consider the extra effect of wind and solar radiation in addition to relative humidity and air temperature for measuring thermal comfort showed the highest correlations with UTCI. In a recent study [12] the authors also found a significant better fit of 

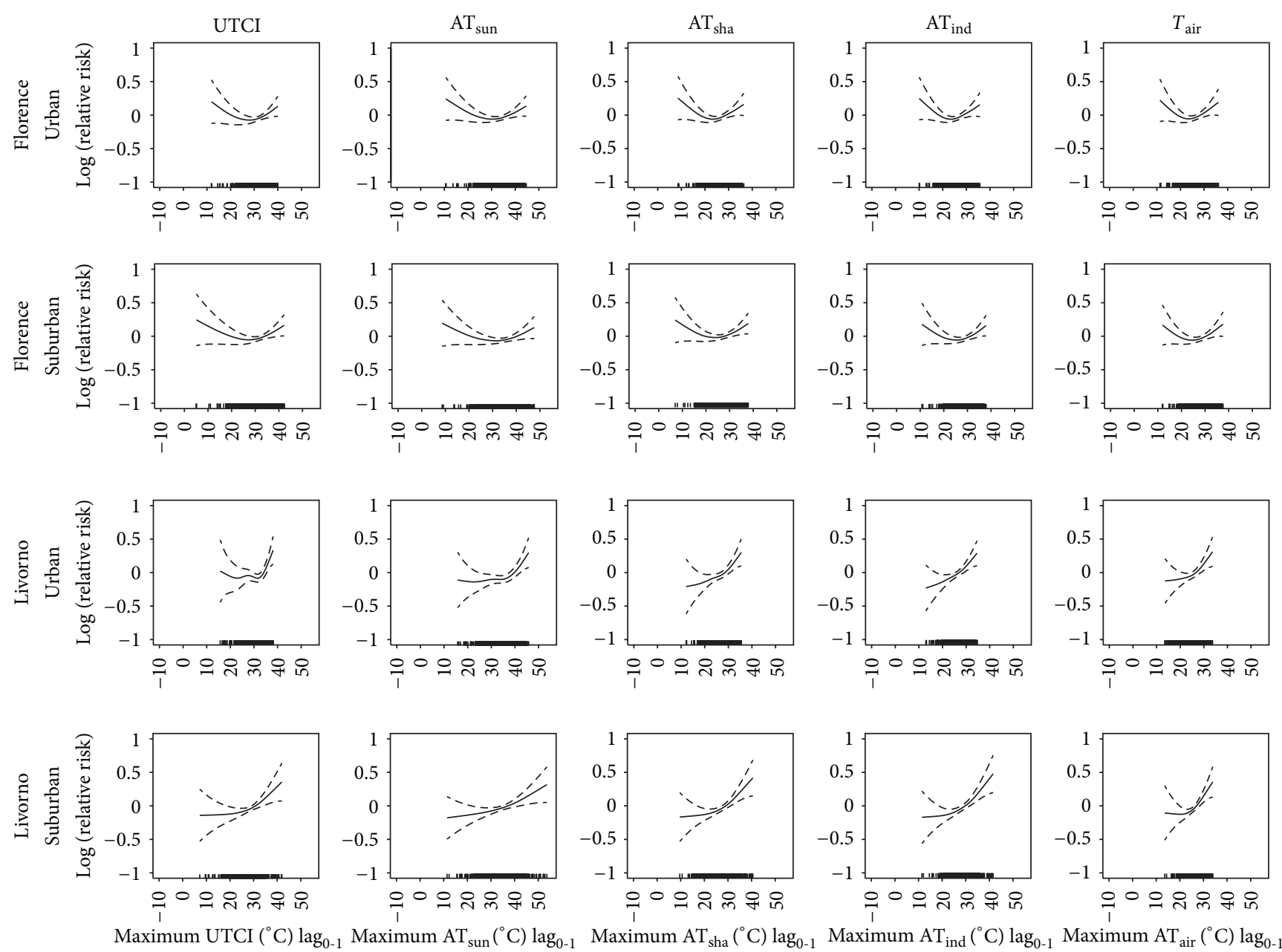

FIGURE 2: Relationships between daily maximum thermal predictors $\left(\operatorname{lag}_{0-1}\right)\left({ }^{\circ} \mathrm{C}\right)$ and mortality of the very elderly (subjects $\geq 75$ years of age) in an inland city (Florence) and coastal-plain city (Livorno). Relationships estimated by using urban and suburban meteorological data for the period 2006-2008 (May-October). UTCI: Universal Thermal Climate Index; $\mathrm{AT}_{\text {sun }}$ : apparent temperature assessed outdoors also taking the solar radiation contribution into account; $\mathrm{AT}_{\text {sha }}$ : apparent temperature assessed outdoors in the shade; $\mathrm{AT}_{\text {ind }}$ : apparent temperature assessed in indoor conditions; $T_{\text {air }}$ : environmental temperature. Analyses were controlled for air pollution concentrations, daylight hours, year, day of the week, public holidays, and summer population decrement.

three-parameter AT (the version which also accounts for the extra effect of wind speed, called $\mathrm{AT}_{\text {sha }}$ in this study) with UTCI than other simple two-parameter indices, such as the Heat Index, the Humidex, or the Wet-Bulb Globe Temperature. In particular, the authors observed a correlation coefficient of $95.35 \%$, slightly lower than the mean values of $96.46 \%$ and $96.67 \%$ highlighted in this study when daily average and minimum values were considered, respectively. However, it was also higher than the correlation coefficient of $88.16 \%$ found in this study when daily maximum values were used. Blazejczyk et al. [12] also evidenced a lower slope coefficient, 0.716 , than the very good ones detected in this study, 1.000, 1.028, and 0.922, when mean average, minimum, and maximum values were taken into account. This probably depends on the different dataset characteristics of the meteorological variables used in both studies. The correlation and slope coefficients between simple, direct twoparameter indices (Heat Index, Humidex or Wet-Bulb Globe
Temperature) and UTCI found in the Blazejczyk et al. [12] study were lower than those observed in this study, probably due to the fact that the thermal indices used required a more restrictive air temperature range of application (calculated for air temperature $>20^{\circ} \mathrm{C}$ ) than in this study in which the simple, direct two-parameter index used $\left(\mathrm{AT}_{\text {ind }}\right)$ was applicable over a wide range of temperatures (no temperature restrictions were considered).

In conclusion, the authors also reported that direct indices (i.e., AT) are less correlated with UTCI than indices derived from various human heat budget models, such as the Perceived Temperature, the Physiological Equivalent Temperature, or the Standard Effective Temperature. One of the possible reasons for the noncompliance is the lack of the radiation factor in the equations [12]. However, these authors did not apply the four-parameter AT version [24] which also includes the extra effect of solar radiation $\left(\mathrm{AT}_{\text {sun }}\right)$. The $\mathrm{AT}_{\text {sun }}$ revealed the best relationships with UTCI among 

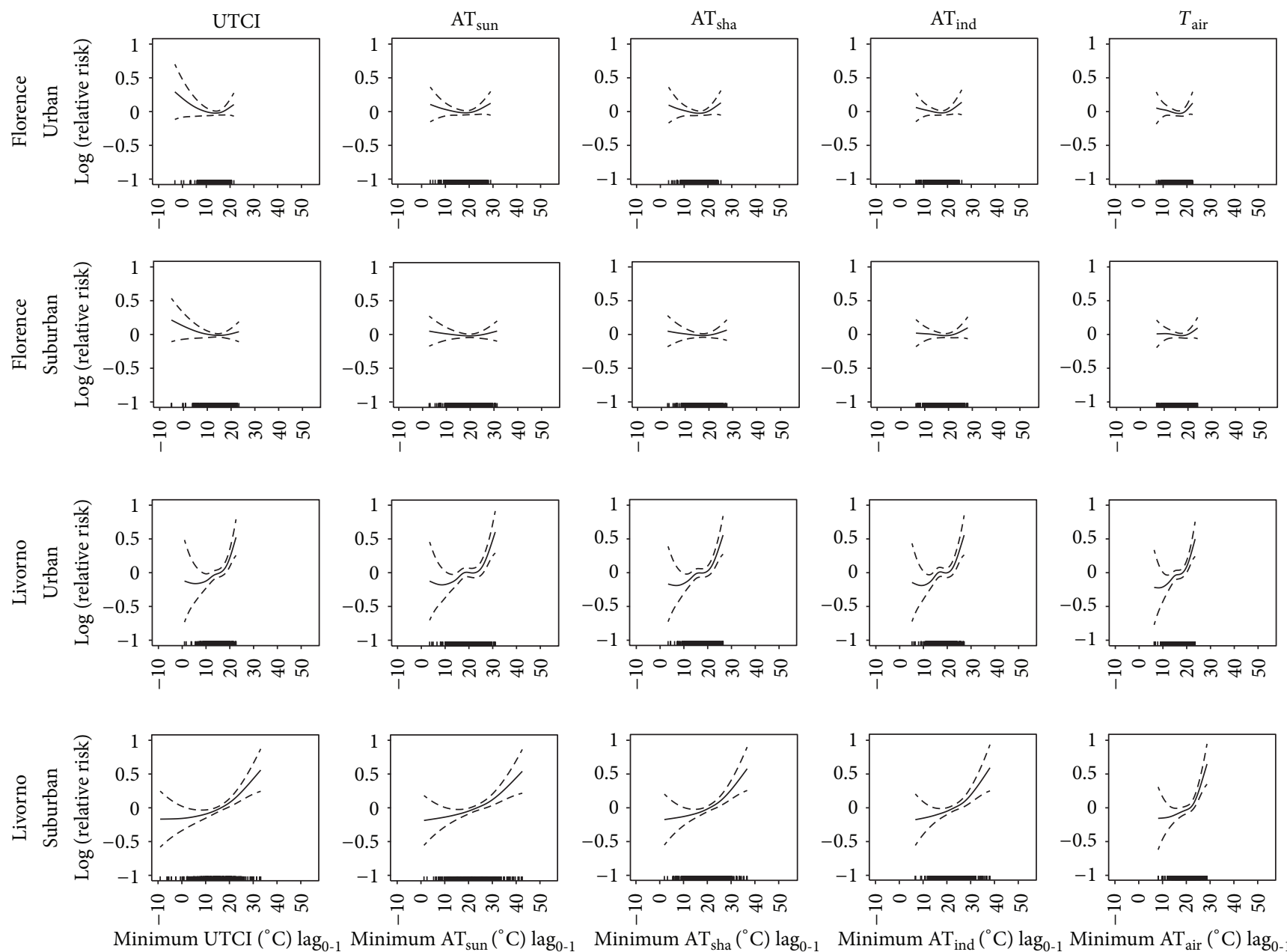

FIGURE 3: Relationships between daily minimum thermal predictors $\left(\operatorname{lag}_{0-1}\right)\left({ }^{\circ} \mathrm{C}\right)$ and mortality of the very elderly (subjects $\geq 75$ years of age) in an inland city (Florence) and coastal-plain city (Livorno). Relationships estimated by using urban and suburban meteorological data for the period 2006-2008 (May-October). UTCI: Universal Thermal Climate Index; AT $_{\text {sun }}$ : apparent temperature assessed outdoors also taking the solar radiation contribution into account; $\mathrm{AT}_{\text {sha }}$ : apparent temperature assessed outdoors in the shade; $\mathrm{AT}_{\text {ind }}$ : apparent temperature assessed in indoor conditions; $T_{\text {air }}$ : environmental temperature. Analyses were controlled for air pollution concentrations, daylight hours, year, day of the week, public holidays, and summer population decrement.

the thermal indicators considered when daily average and maximum values were used in this study.

The reason behind the higher correlation coefficient of the direct three- and four-parameter indices with UTCI recorded in this study, compared to other more simple, direct two-parameter indices or the individual air temperature, is only due to the inclusion of the extra effect of wind speed in $\mathrm{AT}_{\text {sha }}$ and the global radiation in $\mathrm{AT}_{\text {sun }}$. The inclusion of these parameters in the thermal comfort assessment allows a better and more complete representation of the thermal environment as considered when using UTCI. This is also confirmed by the fact that when maximum thermal indices and air temperature indicators were compared with UTCI, the $\mathrm{AT}_{\text {sun }}$, which also considers the radiant solar contribution for outdoor thermal comfort evaluation, was the only indicator to show a high correlation coefficient value $>90 \%$. Conversely, when daily minimum values were considered, the solar radiation contribution assumed less importance and both $\mathrm{AT}_{\text {sun }}$ and $\mathrm{AT}_{\text {sha }}$ showed similar high correlations with UTCI. Furthermore, in these conditions, simple two-parameter indices, such as $\mathrm{AT}_{\text {ind }}$, also showed high correlation coefficients with UTCI (over 90\%).

\subsection{Exposure-Response Curves between Mortality and each} Thermal Indicator. Both cities showed two well-known shaped short-term relationships between different thermal indicators and mortality of the very elderly (aged $\geq 75$ ), already evidenced in many previous studies $[3,34,35]$. In this study, these relationships were studied over a wider "warm" period (from May to October) than that generally considered in previous studies (from June to August) to detect the association between heat and mortality. The reason for this choice was that the area studied is often subjected to "anomalous" heat stress conditions that can also occur earlier, during the average/late spring months (such as May/June) or later, during the early/average autumn months 
(September/October). By way of example, during May of 2007 and May and September of 2008, the inland plain city also experienced several days with very high (for the period) maximum air temperatures, close to or slightly higher than $27^{\circ} \mathrm{C}$. It is known that an equivalent high daily temperature could be more dangerous in May, when people are not still acclimatized to the heat, than in August, because very high temperatures are unusual that early in the season [36].

Exposure-response curves between total mortality and different thermal indicators clearly showed different shapes at a regional scale, with stepper right-hand slope curves (heat effects on mortality) in the milder coastal plain city. These patterns were already evidenced in a previous study [3] and the authors concluded that a population living at the coast is more susceptible to the heat and less adaptable to sudden temperature changes and heat extremes. This is because the coastal city generally shows reduced daily temperature ranges and lower temperature variations during the warmest period of the year than the inland city.

As already reported in a previous Korean study [15], similar exposure response curves between all-cause mortality and a simple daily mean, maximum, and minimum direct index (the $\mathrm{AT}_{\text {ind }}$ ) and $\mathrm{T}_{\text {air }}$ were observed in two different Korean cities (one inland and one seashore cities). This is in agreement with our study, where the curves obtained with different indicators had similar shapes. However, the Korean study also showed different curves when another rational index (the Perceived Temperature) was used as an indicator. This situation has not been confirmed in this study, where a more advanced rational index (UTCI) was applied.

Our study also showed that all thermal rational and direct indices assessed and the air temperature measured by using meteorological data recorded by weather stations located in urban and suburban areas might have heterogeneous relationships with mortality in the coastal city. In another Italian study [37] which evaluated the association between mortality and heat measured by using airport and city-centre temperatures, the authors found that in two cities (Rome and Turin) the exposure values were very similar, while in another city (Milan) the AT differed greatly between stations. Therefore, it is also plausible to expect dissimilar heat-related mortality results when different sources of meteorological data are used in epidemiological environmental studies. For this reason, studies assessing the potential impact of heat on mortality need to take different environmental exposure contexts into account, that is, meteorological data recorded by urban or suburban weather stations, in order to ensure more accurate estimates of health effects on the population.

4.3. The Selection of the Best Thermal Indicator of Heat-Related Mortality in Different Geographical Areas. At the present time, only a few recent studies have tried to investigate the effect of various thermal indictors on mortality data $[14,15$, 17-19] in the aim of selecting the best predictor of mortality. Currently, great uncertainty surrounds the establishing of the most appropriate thermal indicator, as well as the daily temporal characteristic (daily average, maximum, or minimum values) for best fitting the thermal impact on mortality.
A previous study carried out in US cities [17] and two in Australian cities $[18,19]$ found that no single temperature measure was superior to the others. One reason advanced by several authors [17] was the high correlation among different thermal indicators showing the same predictive ability. However, these studies only used individual meteorological parameters or simple, direct two- or three-parameter indices as potential indicators of mortality. Furthermore, the analyses were not controlled for air pollution in the American study, while the Australian studies controlled for $\mathrm{PM}_{10}, \mathrm{NO}_{2}$, and $\mathrm{O}_{3}$. In another study carried out in two Korean cities [15], the authors investigated the effect on mortality, also controlled for $\mathrm{PM}_{10}$ and $\mathrm{O}_{3}$, by using a rational index, the Perceived Temperature based on a human heat budget model, compared with other simple direct indices or air temperature indicators. The authors found that in terms of model fitting by AIC, for one city (Seoul), the daily maximum Perceived Temperature was the best predictor for the allcause mortality risk. The interpretation of the authors is that, because the city of Seoul is located near the sea, the Perceived Temperature, which also includes the humidity effect, was a better indicator of excess mortality than the air temperature. This is also confirmed by the fact that the two other best model indicators found for Seoul always accounted for the humidity effect (daily mean Perceived Temperature and minimum AT). Conversely, the worst indicator of total mortality included the daily maximum air temperature. However, because different results were also observed for another city, the authors concluded that the rational and direct indices used in the study do not always act as the best predictors for the assessment of heat-related mortality [15]. In a more recent study [14] conducted in Taiwan, the authors identified the apparent temperature index, assessed in the form of a three-parameter AT index, as the most optimal hightemperature index associated with all-cause mortality. The AT was selected as the best model from among eight hightemperature indices, including three single air temperature measurements (average, maximum, and minimum) and five different simple, direct indices.

In this study, our findings partially confirm several results of the Korean study and are in firm agreement with the Lin et al. [14] conclusion. Indeed, direct multivariate indices $\left(\mathrm{AT}_{\text {sun }}\right.$ and $\left.\mathrm{AT}_{\text {sha }}\right)$, which also account for the extra effect of wind speed and/or solar radiation, as well as the combined contribution of humidity and air temperature, were selected as the best predictors for all-cause very-elderly mortality risk in the inland plain city (daily average $\mathrm{AT}_{\text {sun }}$ ) and the coastal city (daily minimum $\mathrm{AT}_{\text {sha }}$ ). In particular, the probability of being the best predictive model among the other candidate models considered in this study was nearly (in the inland plain city) or above (in the coastal plain city) $50 \%$.

However, the UTCI was never identified as the best thermal predictor of all-cause very-elderly mortality in this study. This is probably due to the specific characteristics of UTCI, which includes a complex multinode model of thermoregulation coupled with a clothing model that determines strong thermal sensitivity greatly influenced by the immediate surroundings. For this reason, the UTCI naturally represents the best approach for exhaustive thermal comfort 
studies. However, it also requires accurate micrometeorological measurements of a specific location and subjective information (clothing thermal and physical activity characteristics) which is not generalized for epidemiological studies over wide geographical areas (such as cities), where great, uncontrolled variability and different types of human behavior exist. For this reason simplified approaches for thermal comfort assessment for a wide set of people have been preferred.

However, although the use of direct multivariate (fouror three-parameter) indices revealed the best fitting with all-cause very-elderly mortality attributable to heat stress, different multivariate index indicators were identified in both cities. For example, the urban average $\mathrm{AT}_{\text {sun }}$, identified as the best predictive model for the inland plain city, also showed a poor predictive power for the coastal city. The same was also observed for the best indicator identified for the coastal city. Consequently, our findings suggest the use of direct multivariate indices as indicators naturally recommended for epidemiological heat-related mortality studies especially when the very elderly are considered; however, the choice of the most appropriate multivariate thermal index should be based on the geographical characteristics of the place investigated and the data available. In the inland plain city, the use of a full direct index is suggested which also accounts for the extra solar radiation contribution, besides the other meteorological effects. In other terms, because the extra effect of wind speed and relative humidity is more prevalent in a coastal city than in an inland city, the use of three- $\left(T_{\text {air }}, \mathrm{RH}\right.$, and $\left.V_{10}\right)$ or also direct two-parameter ( $T_{\text {air }}$ and $\mathrm{RH}$ ) indices is sufficient for obtaining an effective prediction of heat-related mortality.

Furthermore, this study also showed that thermal indices measured by an urban meteorological station in both cities had a greater relationship with heat-related mortality than thermal indices measured by a suburban station, even though no real break exists between urban and suburban areas. However, it was not possible to identify an unequivocal daily temporal characteristic (daily average, maximum, or minimum values) of thermal index measurements for both cities. Indeed, daily average and minimum thermal index indicators were identified as the best models in the inland and coastal cities, respectively. Several researchers [38] reported that the use of the daily average temperature as an exposure indicator of thermal conditions, taking the whole day and night into account, generally provides more easily interpreted results within a policy context. In another study [39], the authors also found a close association of the minimum temperature with heat effects. The impact might also be the strongest when the very elderly are considered: when heat discomfort conditions also persist during night-time hours, when the body generally requires physiological rest, and when renal tubular conservation of sodium and water diminishes during periods of dehydration, all of which represent aggravating factors for health, especially in the "elderly frail" with a significant increase in the mortality risk. Conversely, daily maximum indicators represent the worst model-fits in the coastal city. This is probably due to the fact that cities on the coast generally have reduced daily temperature ranges and less frequent daily "extremes" than inland cities.

4.4. Strengths and Limitations. This study has several strengths. Firstly, the newly developed UTCI, which represents the state-of-the-art of outdoor thermal comfort assessment, has been included, together with other thermal indices, as a potential predictor of heat-related mortality. Secondly, an accurate model selection was carried out by using the Akaike weight scheme which is a useful tool for supplementing the basic results obtained with the AIC model comparison analysis [31]. The analyses were controlled for the main air pollution concentrations as confounding effects. Previous studies reported differences between models with and without the adjustment of air pollution, especially in the case of extremely hot days and vulnerable groups [40, 41].

Some limitations should also be pointed out. Since the identification of the best thermal predictor of heat-related mortality was only investigated in two cities in this study, the results cannot be applied to other countries and/or climates. Indeed, the interaction between weather and human health is mediated by socioeconomical and cultural (i.e., clothing and diet) factors, besides adaptation of the population to the local climate. However, it should also be noted that the two cities considered in this study had two clearly different climate conditions. In a recent study [42] the authors showed how elderly patients who are living alone and also using community care services are two times more at heat-related health risk than other elderly people. Living alone, also associated with critical health and low socioeconomic status, can generally result in a significant increase in vulnerability to heat conditions. Further improvements could be provided in heat-related health risk estimations by taking socioeconomic conditions, perceptions, and cost factors of using air-conditioning at home during the warmest period of the year and cultural differences into consideration.

In addition, the analyses could also be extended to different mortality categories and age groups. In this way it would be possible to understand if different age and mortality categories are sensitive to different thermal indicators.

\section{Conclusion}

This study showed how the use of direct multivariate indices, which also account for the extra effect of wind speed and/or solar radiation as well as the combined contribution of air humidity and temperature, revealed the best fitting with all-cause very-elderly mortality attributable to heat stress. However, different multivariate thermal index predictors were identified in both inland and coastal plain cities. In addition, UTCI, which represents the best performing index in thermal comfort assessment, was never identified as the best predictor of all-cause very-elderly mortality. It is hypothesized that simplified approaches for a general thermal comfort assessment, such as direct multivariate thermal indices, are preferable for epidemiological purposes. The choice of the most appropriate multivariate thermal index as a predictor of heat-related mortality should be based on geographical characteristics and the availability data 
regarding the area considered. Further studies are needed to confirm these results. The better understanding of the impact of different thermal indicators on mortality in different geographical contexts will provide relevant information for developing efficient public health programs and heat-related health risk assessments. This information could prove to be very useful in developing preventive measures and for functional implementation to improve previous local public health emergency plans related to heat conditions.

\section{Abbreviations \\ UTCI: Universal Thermal Climate Index \\ AIC: Akaike's Information Criterion \\ $w_{i}$ (AIC): Akaike weights \\ AT: Apparent temperature \\ $\mathrm{AT}_{\text {sun }}$ : Apparent temperature assessed outdoors, also taking the solar radiation contribution into consideration \\ $\mathrm{AT}_{\text {sha }}$ : Apparent temperature assessed outdoors in the shade \\ $\mathrm{AT}_{\text {ind }}$ : Apparent temperature assessed in indoor conditions \\ $T_{\text {air }}: \quad$ Environmental temperature \\ RH: $\quad$ Relative humidity \\ $e: \quad$ Water vapor pressure \\ $V_{10}: \quad 10 \mathrm{~m}$ high horizontal wind speed \\ GR: $\quad$ Global radiation.}

\section{Conflict of Interests}

The authors declare that there is no conflict of interests regarding the publication of this paper.

\section{Acknowledgments}

This study was supported and funded by the Regional MeteoSalute Project, Regional Health System of Tuscany, and the Smart HealthyENV Project "Smart Monitoring Integrated System for a Healthy Urban ENVironment in Smart Cities," POR CReO FESR 2007/2013. The authors wish to thank Dr. Paolo Francesconi and Dr. Francesco Profili of the Agenzia Regionale di Sanità della Toscana for providing health data.

\section{References}

[1] R. Basu, "High ambient temperature and mortality: a review of epidemiologic studies from 2001 to 2008," Environmental Health, vol. 8, no. 1, article 40, 2009.

[2] S. Hajat and T. Kosatky, "Heat-related mortality: a review and exploration of heterogeneity," Journal of Epidemiology and Community Health, vol. 64, no. 9, pp. 753-760, 2010.

[3] M. Morabito, A. Crisci, M. Moriondo et al., "Air temperaturerelated human health outcomes: current impact and estimations of future risks in Central Italy," Science of the Total Environment, vol. 441, pp. 28-40, 2012.

[4] A. Tobias, B. Armstrong, I. Zuza, A. Gasparrini, C. Linares, and J. Diaz, "Mortality on extreme heat days using official thresholds in Spain: a multi-city time series analysis," BMC Public Health, vol. 12, no. 1, article 133, 2012.

[5] W. Wu, Y. Xiao, G. Li et al., “Temperature-mortality relationship in four subtropical Chinese cities: a time-series study using a distributed lag non-linear model," Science of the Total Environment, vol. 449, pp. 355-362, 2013.

[6] M. S. Goldberg, A. Gasparrini, B. Armstrong, and M.-F. Valois, "The short-term influence of temperature on daily mortality in the temperate climate of Montreal, Canada," Environmental Research, vol. 111, no. 6, pp. 853-860, 2011.

[7] I. Gómez-Acebo, J. Llorca, P. Rodríguez-Cundín, and T. Dierssen-Sotos, "Extreme temperatures and mortality in the North of Spain.," International Journal of Public Health, vol. 57, pp. 305-313, 2012.

[8] S. P. Almeida, E. Casimiro, and J. Calheiros, "Effects of apparent temperature on daily mortality in Lisbon and Oporto, Portugal," Environmental Health, vol. 9, no. 1, article 12, 2010.

[9] M. Morabito, F. Profili, A. Crisci, P. Francesconi, G. F. Gensini, and S. Orlandini, "Heat-related mortality in the Florentine area (Italy) before and after the exceptional 2003 heat wave in Europe: an improved public health response?" International Journal of Biometeorology, vol. 56, pp. 801-810, 2012.

[10] J. Madrigano, M. A. Mittleman, A. Baccarelli et al., "Temperature, myocardial infarction, and mortality: effect modification by individual- and area-level characteristics," Epidemiology, vol. 24, pp. 439-446, 2013.

[11] T. I. Sung, P. C. Wu, S. C. Lung, C. Y. Lin, M. J. Chen, and H. J. $\mathrm{Su}$, "Relationship between heat index and mortality of 6 major cities in Taiwan," Science of the Total Environment, vol. 442, pp. 275-281, 2013.

[12] K. Blazejczyk, Y. Epstein, G. Jendritzky, H. Staiger, and B. Tinz, "Comparison of UTCI to selected thermal indices," International Journal of Biometeorology, vol. 56, no. 3, pp. 515535, 2012.

[13] R. G. Steadman, “The assessment of sultriness. Part II: effects of wind, extra radiation and barometric pressure on apparent temperature," Journal of Applied Meteorology, vol. 18, no. 7, pp. 874-885, 1979.

[14] Y.-K. Lin, C.-K. Chang, M.-H. Li, Y.-C. Wu, and Y.-C. Wang, "High-temperature indices associated with mortality and outpatient visits: characterizing the association with elevated temperature," Science of the Total Environment, vol. 427-428, pp. 4149, 2012.

[15] Y. M. Kim, S. Kim, H. K. Cheong, and E. H. Kim, "Comparison of temperature indexes for the impact assessment of heat stress on heat-related mortality," Journal of Toxicology and Environmental Health, vol. 26, Article ID e2011009, 2011.

[16] G. Jendritzky, R. de Dear, and G. Havenith, "UTCI-Why another thermal index?" International Journal of Biometeorology, vol. 56, no. 3, pp. 421-428, 2012.

[17] A. G. Barnett, S. Tong, and A. C. A. Clements, "What measure of temperature is the best predictor of mortality?" Environmental Research, vol. 110, no. 6, pp. 604-611, 2010.

[18] P. Vaneckova, G. Neville, V. Tippett, P. Aitken, G. Fitzgerald, and S. Tong, "Do biometeorological indices improve modeling outcomes of heat-related mortality?" Journal of Applied Meteorology and Climatology, vol. 50, no. 6, pp. 1165-1176, 2011.

[19] W. Yu, Y. Guo, X. Ye et al., "The effect of various temperature indicators on different mortality categories in a subtropical city of Brisbane, Australia," Science of the Total Environment, vol. 409, no. 18, pp. 3431-3437, 2011. 
[20] D. Nuvolone, D. Balzi, M. Chini, D. Scala, F. Giovannini, and A. Barchielli, "Short-Term association between ambient air pollution and risk of hospitalization for acute myocardial infarction: results of the cardiovascular risk and air pollution in Tuscany (RISCAT) study," American Journal of Epidemiology, vol. 174, no. 1, pp. 63-71, 2011.

[21] D. Nuvolone, D. Balzi, P. Pepe et al., "Ozone short-term exposure and acute coronary events: a multicities study in Tuscany (Italy)," Environmental Research, vol. 126, pp. 17-23, 2013.

[22] R. G. Steadman, "The assessment of sultriness. Part I. A temperature-humidity index based on human physiology and clothing science," Journal of Applied Meteorology, vol. 18, no. 7, pp. 861-873, 1979.

[23] R. G. Steadman, "A universal scale of apparent temperature," Journal of Climate \& Applied Meteorology, vol. 23, no. 12, pp. 1674-1687, 1984.

[24] R. G. Steadman, "Norms of apparent temperature in Australia," Australian Meteorological Magazine, vol. 43, no. 1, pp. 1-16, 1994.

[25] P. Bröde, K. Blazejczyk, D. Fiala et al., "The universal thermal climate index UTCI compared to ergonomics standards for assessing the thermal environment," Industrial Health, vol. 51, pp. 16-24, 2013.

[26] A. Matzarakis, F. Rutz, and H. Mayer, "Modelling radiation fluxes in simple and complex environments: basics of the RayMan model," International Journal of Biometeorology, vol. 54, no. 2, pp. 131-139, 2010.

[27] T. J. Hastie and N. J. Tibshirani, Generalized Additive Models, vol. 43 of Monographs on Statistics and Applied Probability, Chapman \& Hall, London, UK, 1990.

[28] R Development Core Team, R: A Language and Environment For Statistical Computing, R Foundation for Statistical Computing, Vienna, Austria, 2011, http://www.R-project.org/.

[29] S. N. Wood, Generalized Additive Models: An Introduction With $R$, Chapman \& Hall/CRC, Boca Raton, Fla, USA, 2006.

[30] H. Akaike, "Information theory and an extension of the maximum likelihood principle," in Proceedings of the 2nd International Symposium on Information Theory, B. N. Petrov and F. Caski, Eds., pp. 267-281, Akademiai Kiado, Budapest, Hungary, 1973.

[31] E.-J. Wagenmakers and S. Farrell, "AIC model selection using Akaike weights," Psychonomic Bulletin and Review, vol. 11, no. 1, pp. 192-196, 2004.

[32] A. D. R. McQuarrie and C. L. Tsai, Regression and Time Series Model Selection, World Scientific, Singapore, 1998.

[33] H. Akaike, "On the likelihood of a time series model.," The Statistician, vol. 27, pp. 217-235, 1978.

[34] A. Ishigami, S. Hajat, R. S. Kovats et al., "An ecological timeseries study of heat-related mortality in three European cities," Environmental Health, vol. 7, article 5, 2008.

[35] R. Bustinza, G. Lebel, P. Gosselin, D. Bélanger, and F. Chebana, "Health impacts of the July 2010 heat wave in Québec, Canada," BMC Public Health, vol. 13, article 56, 2013.

[36] K. Zhang, R. B. Rood, G. Michailidis et al., "Comparing exposure metrics for classifying "dangerous heat" in heat wave and health warning systems," Environment International, vol. 46, pp. 23-29, 2012.

[37] F. K. De'donato, M. Stafoggia, M. Rognoni et al., "Airport and city-centre temperatures in the evaluation of the association between heat and mortality," International Journal of Biometeorology, vol. 52, no. 4, pp. 301-310, 2008.
[38] B. G. Anderson and M. L. Bell, "Weather-related mortality: how heat, cold, and heat waves affect mortality in the United States," Epidemiology, vol. 20, no. 2, pp. 205-213, 2009.

[39] P. L. Kinney, M. S. O’Neill, M. L. Bell, and J. Schwartz, "Approaches for estimating effects of climate change on heatrelated deaths: challenges and opportunities," Environmental Science and Policy, vol. 11, no. 1, pp. 87-96, 2008.

[40] D. G. C. Rainham and K. E. Smoyer-Tomic, "The role of air pollution in the relationship between a heat stress index and human mortality in Toronto," Environmental Research, vol. 93, no. 1, pp. 9-19, 2003.

[41] Y. Kim and S. Joh, "A vulnerability study of the low-income elderly in the context of high temperature and mortality in Seoul, Korea," Science of the Total Environment, vol. 371, no. 1-3, pp. 82-88, 2006.

[42] Y. Zhang, M. Nitschke, and P. Bi, "Risk factors for direct heatrelated hospitalization during the 2009 Adelaide heatwave: a case crossover study," Science of the Total Environment, vol. 442, pp. 1-5, 2013. 


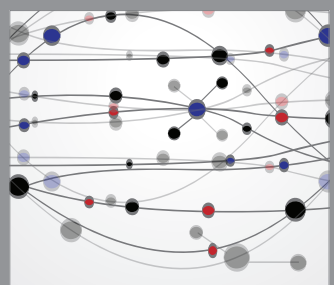

The Scientific World Journal
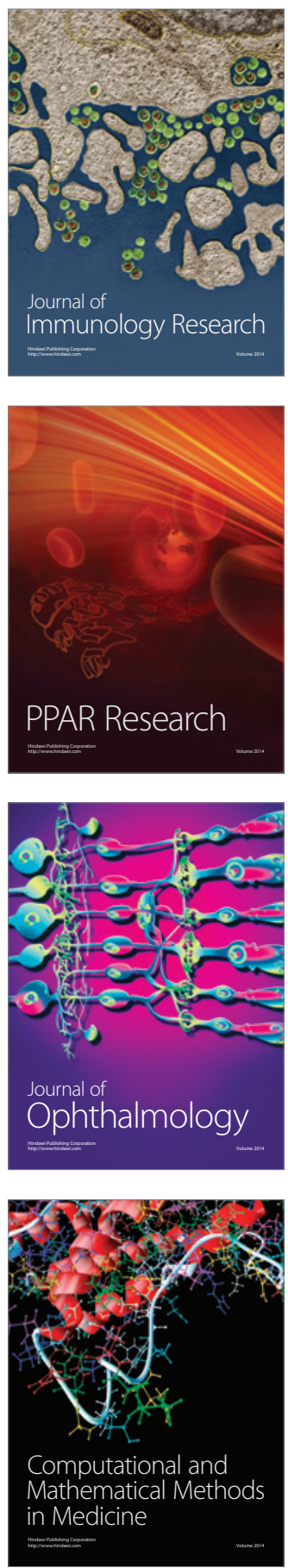

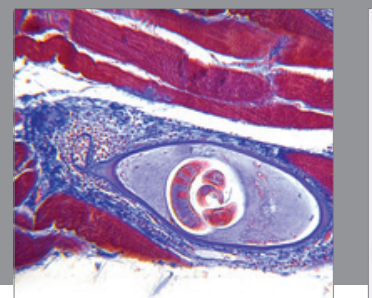

Gastroenterology

Research and Practice
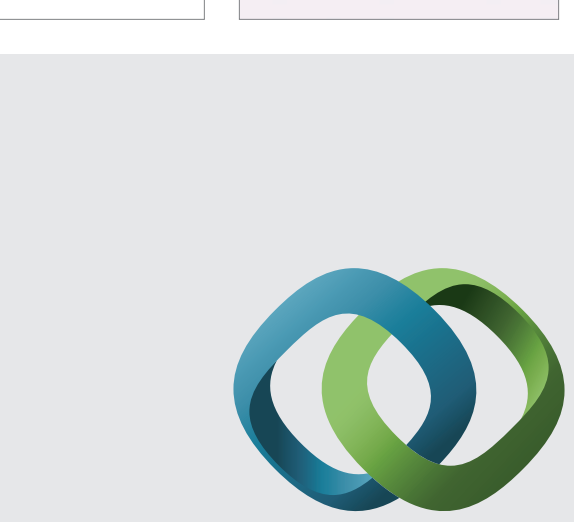

\section{Hindawi}

Submit your manuscripts at

http://www.hindawi.com
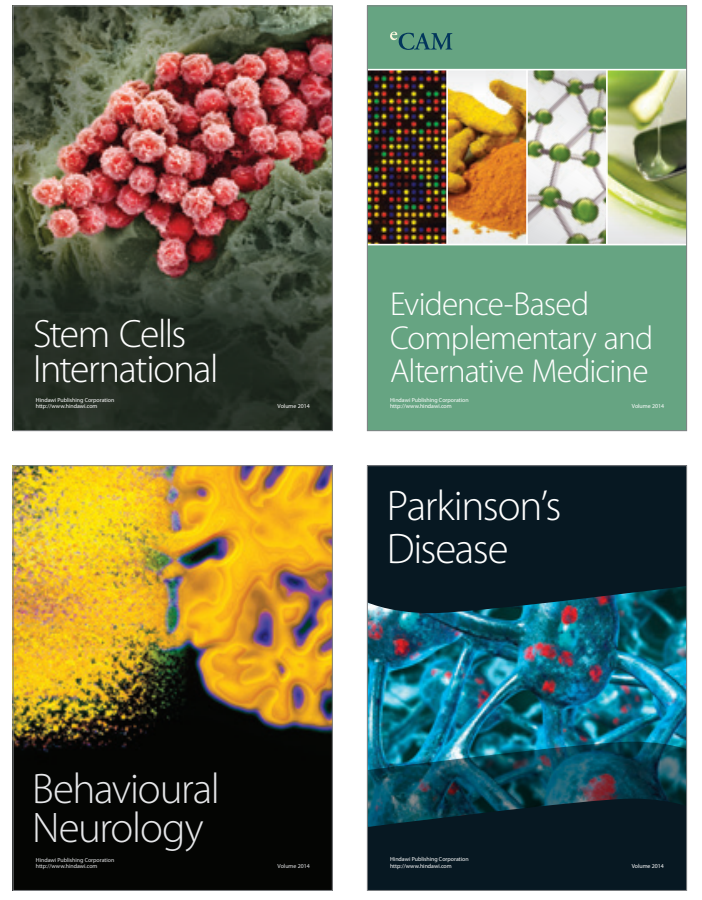
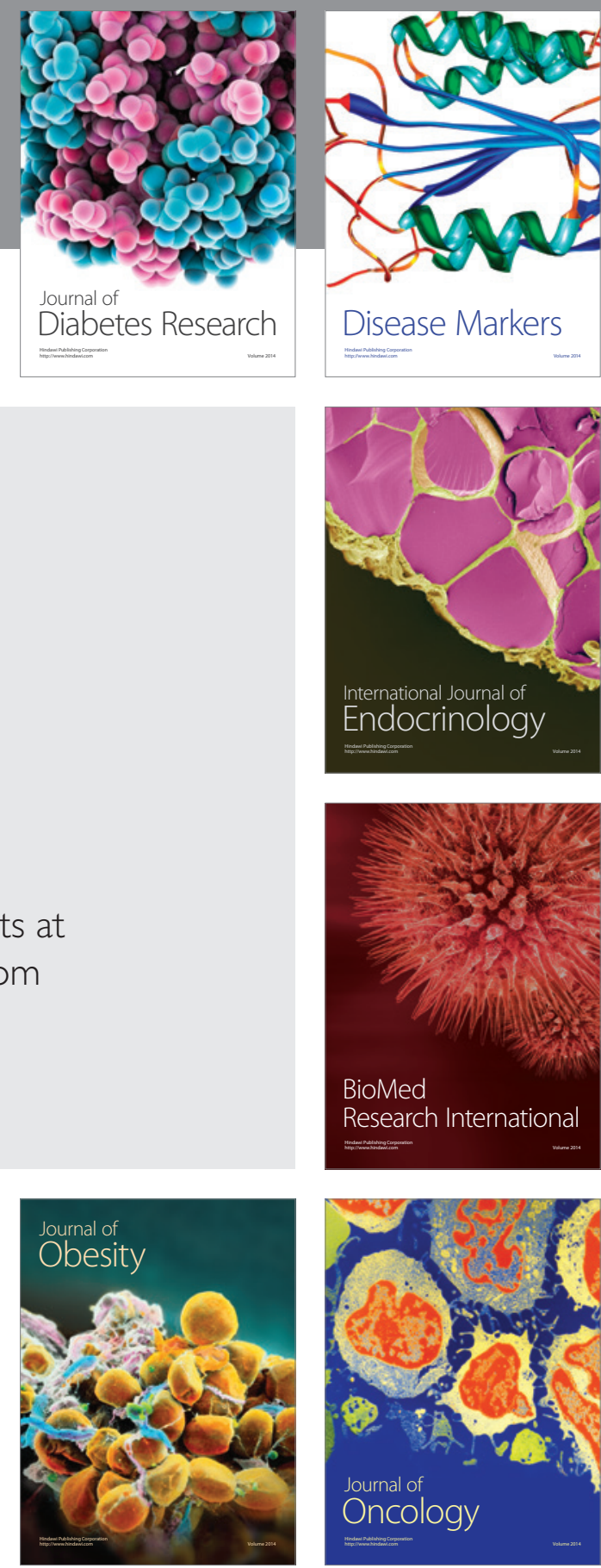

Disease Markers
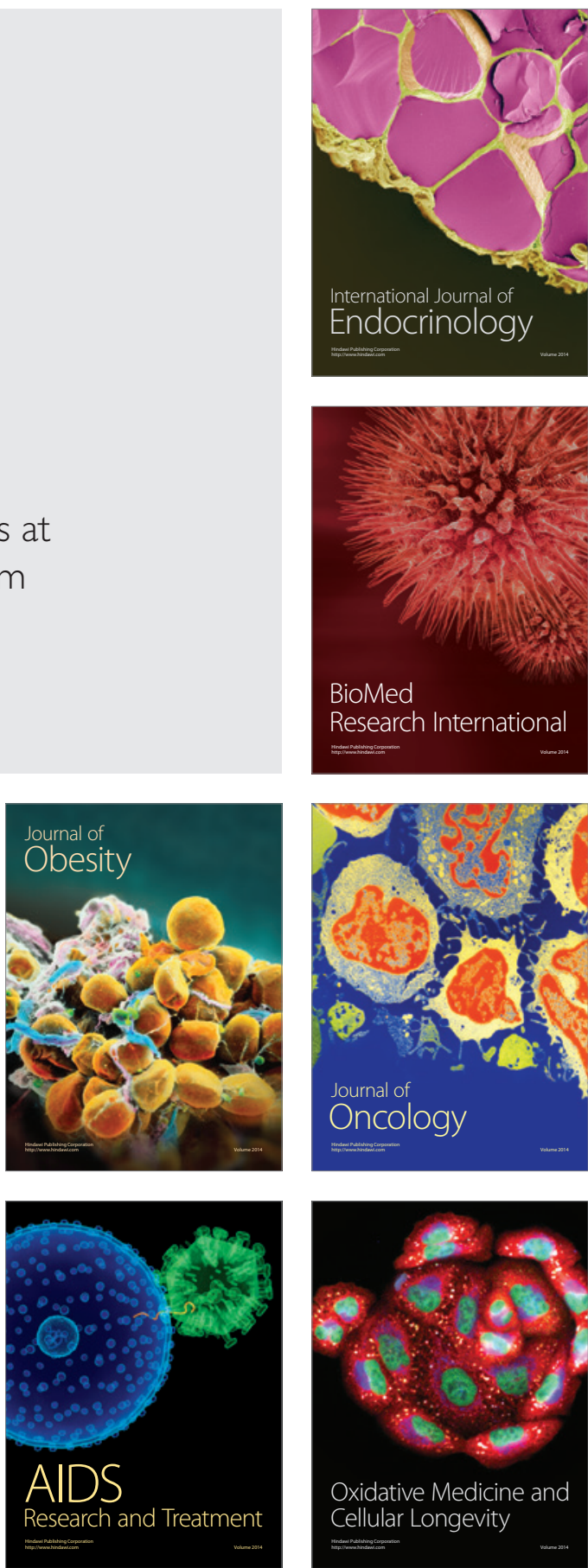